OPEN ACCESS

Edited by:

Akio Kanai,

Keio University, Japan

Reviewed by:

Isidore Rigoutsos,

Thomas Jefferson University,

United States

Naoki Shigi,

National Institute of Advanced

Industrial Science and

Technology (AIST), Japan

${ }^{*}$ Correspondence:

Anita K. Hopper

hopper.64@osu.edu

Specialty section:

This article was submitted to

RNA,

a section of the journal

Frontiers in Genetics

Received: 30 October 2018 Accepted: 29 January 2019 Published: 20 February 2019

Citation:

Hopper AK and Nostramo RT (2019) tRNA Processing and

Subcellular Trafficking

Proteins Multitask in

Pathways for Other RNAs.

Front. Genet. 10:96.

doi: 10.3389/fgene.2019.00096

\section{tRNA Processing and Subcellular Trafficking Proteins Multitask in Pathways for Other RNAs}

\author{
Anita K. Hopper* and Regina T. Nostramo \\ Department of Molecular Genetics, Center for RNA Biology, Ohio State University, Columbus, OH, United States
}

This article focuses upon gene products that are involved in tRNA biology, with particular emphasis upon post-transcriptional RNA processing and nuclear-cytoplasmic subcellular trafficking. Rather than analyzing these proteins solely from a tRNA perspective, we explore the many overlapping functions of the processing enzymes and proteins involved in subcellular traffic. Remarkably, there are numerous examples of conserved gene products and RNP complexes involved in tRNA biology that multitask in a similar fashion in the production and/or subcellular trafficking of other RNAs, including small structured RNAs such as snRNA, snoRNA, 5S RNA, telomerase RNA, and SRP RNA as well as larger unstructured RNAs such as mRNAs and RNA-protein complexes such as ribosomes. Here, we provide examples of steps in tRNA biology that are shared with other RNAs including those catalyzed by enzymes functioning in $5^{\prime}$ end-processing, pseudoU nucleoside modification, and intron splicing as well as steps regulated by proteins functioning in subcellular trafficking. Such multitasking highlights the clever mechanisms cells employ for maximizing their genomes.

Keywords: tRNA, nuclear export, nuclear import, RNA processing, tRNA splicing

\section{INTRODUCTION}

Biogenesis of different categories of eukaryotic RNAs has been thought to proceed via distinct pathways. Indeed, eukaryotic cells employ separate DNA-dependent RNA polymerases, Pol I, II, and III, to transcribe precursors to ribosomal RNA (pre-rRNA), mRNA (pre-mRNA), and tRNA (pre-tRNA), respectively. Moreover, the cell biology for processing the various categories of pre-RNAs appears to be quite different. For example, mRNA splicing, capping, polyadenylation, and nuclear export all occur co-transcriptionally [Review: (Bentley, 2014)]. In contrast, tRNA biogenesis occurs post-transcriptionally at numerous distinct subcellular locations. In S. cerevisiae (budding yeast), pre-tRNA transcription by Pol III and $5^{\prime}$ maturation, catalyzed by RNase P, are located in the nucleolus [Review: (Hopper et al., 2010)], whereas particular tRNA modifications are added in the nucleoplasm, and other modifications are added at the inner nuclear membrane or in the cytoplasm after tRNA nuclear export [Review: (Hopper, 2013)]; moreover, pre-tRNA splicing occurs on the surface of mitochondria (Yoshihisa et al., 2003) (Figure 1). Despite the general requirement for separate DNA-dependent RNA polymerases and the different subcellular locations of major processing events, it is now appreciated that particular RNA processing/ modification enzymes and pathways for intracellular dynamics can be shared among distinct RNA categories to facilitate related, if not identical, functions. Here, we detail well-established 


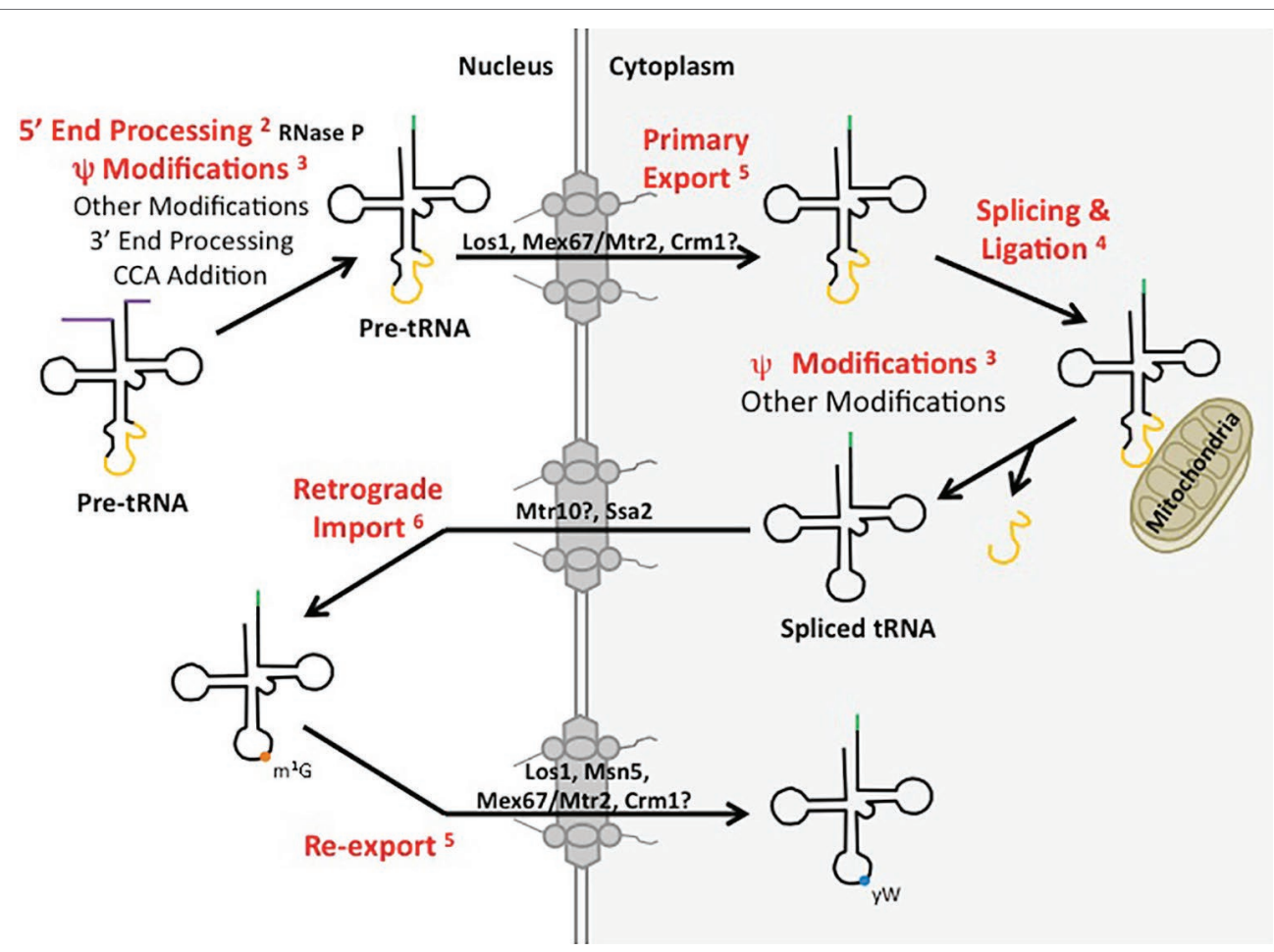

FIGURE 1 | tRNA biogenesis and subcellular trafficking steps multitask in the processing/localization of other RNAs. Yeast tRNAs are synthesized as primary tRNAs (pre-tRNA) in the nucleolus and undergo subsequent $5^{\prime}$ and $3^{\prime}$ end processing, modifications (such as pseudouridine modification) and CCA addition, generating pre-tRNAs. These pre-tRNAs are then exported from the nucleus to the cytoplasm (shaded white and grey, respectively) via Los1, Mex67-Mtr2, or potentially Crm1 in a step termed tRNA primary nuclear export. tRNAs containing an intron are then spliced at the surface of the mitochondria by the SEN complex and the two tRNA halves are ligated by Rlg1/Trl1. Further nucleoside modifications also take place in the cytoplasm. Spliced tRNAs undergo a second trafficking step termed retrograde nuclear import, mediated by Ssa2 and potentially Mtr10. Once back in the nucleus, spliced tRNAs can be modified by enzymes that only recognize spliced tRNAs, and not intron-containing tRNAs, such as Trm5-catalyzed methylation of $\mathrm{G}$ at position 37 ( $\mathrm{m}^{1} \mathrm{G}_{37}$; orange circle). tRNAs are then re-exported from the nucleus to the cytoplasm by any of the primary exporters or Msn5, which functions solely in the re-export step, to be utilized in translation. Certain tRNAs receive additional modifications, such as modification of the $\mathrm{m}^{1} \mathrm{G}_{37}$ to wybutosine (yW; blue circle) in tRNA ${ }^{\text {Phe }}$ in yeast. The tRNA biogenesis and subcellular trafficking steps highlighted in red indicate pathways utilized by not only tRNA, but other RNA species as well. Each is discussed in the text and the appropriate figure numbers are indicated in superscript.

examples (Figure 1, example steps in red font) of proteins and RNP complexes involved in tRNA biology that also function in the biogenesis and subcellular trafficking of other categories of RNAs, RNPs, and proteins.

\section{Shared Subunits for RNPs Involved in 5' Pre-tRNA Processing, Pre-rRNA Processing, and Telomerase}

RNase $\mathrm{P}$ is an endonuclease that removes $5^{\prime}$ leaders from pre-tRNAs (Figure 1). It is a ribonuclear protein (RNP) complex in bacteria, many archaea, and in the nucleus of budding yeast and metazoans; in these organisms, RNase P is comprised of a single small catalytic RNA and various numbers of proteins [Review: (Gopalan et al., 2018)]. Surprisingly, RNase P is a protein-only enzyme (PRORP) in plants and in the organelles of various organisms (Gutmann et al., 2012). In budding yeast, the RNase P complex that processes nucleus-encoded tRNAs is located in the nucleolus and the complex consists of RPR1, the RNA subunit, and nine essential proteins, Pop1, Pop3, Pop4, Pop5, Pop6, Pop7, Pop8, Rpp1, and Rpr2 [Review: (Xiao et al., 2002)]. Unexpectedly, RNase P shares protein subunits with RNPs that have different functions (Figure 2). All RNase $\mathrm{P}$ proteins except Rpr2 and the RPR1 RNA are shared with MRP, a nucleolar RNP that functions in the processing of pre-rRNA (Xiao et al., 2002; Lindahl et al., 2009; Gopalan et al., 2018). Moreover, Pop1, Pop6, and Pop7 are also components of telomerase, the RNP that is required for the replication of chromosome termini (Lemieux et al., 2016). So, several proteins of the RNase P RNP multitask in at least three separate processes. Structural studies have delineated how the various proteins of these three independent RNPs interact with their unshared RNA subunit (Figure 2), but interesting and important questions remain regarding the evolutionary selection for sharing of subunits among these RNPs with quite different functions.

\section{Numerous RNA Substrates for the "tRNA" Pseudouridine Synthetases}

Throughout the steps of pre-tRNA maturation, tRNAs acquire nucleoside modifications. tRNAs are highly modified. There 


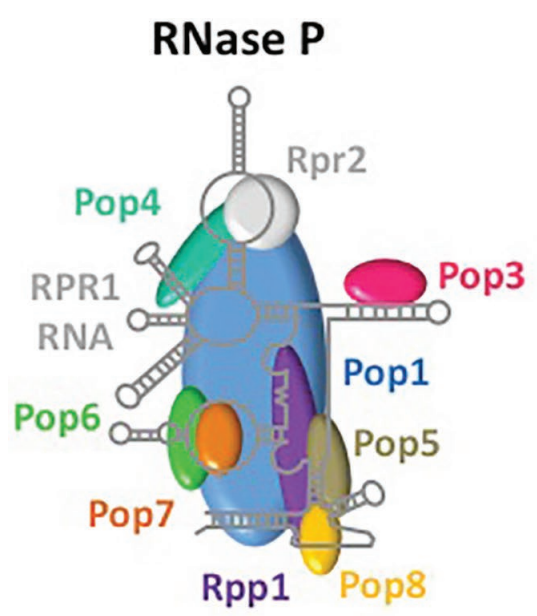

RNase MRP

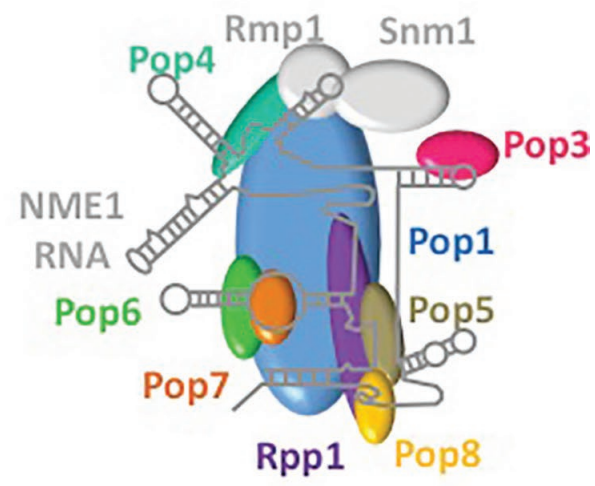

\section{Telomerase}

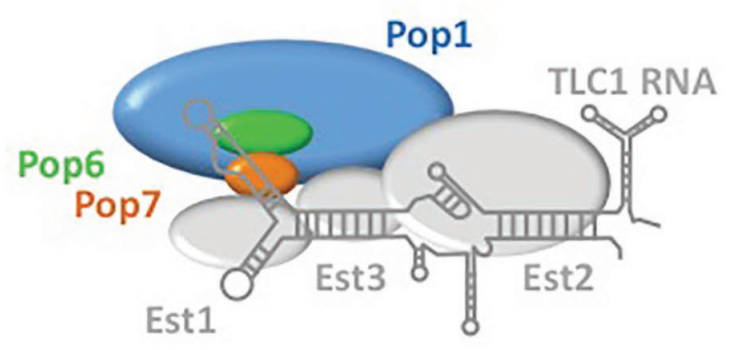

FIGURE 2 | RNase P, RNase MRP, and telomerase share protein subunits. Depicted are the RNA and proteins that comprise the RNPs of RNase P, RNase MRP and telomerase. Pop 1 (blue), Pop6 (green), and Pop7 (orange) are shared among all three RNPs, whereas other proteins are shared only between RNase P and RNase MRP (Pop3, pink; Pop4, teal; Pop5, brown; Pop8, yellow; Rpp1, purple). RNAs and proteins that are unique among each of these complexes are indicated in grey. The structures of RNA and protein components are derived from Lemieux et al. (2016) for telomerase and from Gopalan et al. (2018) for RNase P. The structure of RNase MRP was extrapolated from the RNase P structure.

are $>100$ nucleotide modifications known to occur on tRNAs [Reviews: (Phizicky and Hopper, 2010; Jackman and Alfonzo, 2013)]. Budding yeast has 25 different tRNA modifications, and each mature tRNA contains an average of $\sim 12$ modified nucleosides. Nearly all the genes encoding proteins required for tRNA modification in budding yeast have been identified and characterized (Phizicky and Hopper, 2010; Hopper, 2013). Pseudouridine $(\psi)$ is one of the most abundant of the tRNA modifications. The enzymes that catalyze pseudouridylation of nucleus-encoded cytoplasmic tRNAs (Pus1, Pus3, Pus4, Pus6, Pus7, and Pus8) are protein enzymes (Phizicky and Hopper, 2010). Ribosomal 5S RNA, small nuclear RNAs (snRNA) that are mRNA splicing components, and small nucleolar RNAs (snoRNA) that function in pre-rRNA processing, and rRNAs all also contain pseudouridine modifications. 5S rRNA $\psi$ modification is catalyzed by Pus7 in budding yeast (Decatur and Schnare, 2008). Pseudouridine modifications of snRNA and snoRNA are more complicated as, in addition to $\psi$ modifications being catalyzed by particular Pus proteins, they are also catalyzed by H/ACA pseudouridylases. H/ACA pseudouridylases are RNA-dependent RNP complexes with guide RNAs (yeast H/ACA RNAs). In budding yeast, $\psi$ modifications of snRNAs are catalyzed by Pus1 or Pus7 or by RNA-dependent RNP enzymes, and snoRNAs $\psi$ modifications are catalyzed by Pus1-4 and Pus6,7 in addition to H/ACA pseudouridylases. In contrast, rRNAs pseudouridylation is catalyzed solely by H/ACA pseudouridylases [Reviews: (Karijolich and Yu, 2010; Rintala-Dempsey and Kothe, 2017)] (Figure 3).

New genome-wide technologies have led to the discovery that mRNAs also contain pseudouridine modifications and that the mRNA modifications are generated by both Pus proteins and the H/ACA RNP. Scores of budding yeast mRNAs are modified by the Pus proteins and each of the PUS genes that encode nuclear or cytoplasmic enzymes contributes to mRNA modifications at particular sites. Furthermore, some mRNA sites are modified only under particular stress conditions [(Carlile et al., 2014; Schwartz et al., 2014) Reviews: (Gilbert et al., 2016; Rintala-Dempsey and Kothe, 2017)]. Thus, the protein "tRNA" pseudouridylases multitask in the biogenesis of tRNAs, 5S RNA, snRNAs, snoRNAs, and mRNAs (Figure 3).

\section{Multitasking by Pre-tRNA Splicing Enzymes}

In addition to $5^{\prime}$ and $3^{\prime}$ end-processing and addition of nucleoside modifications, some pre-tRNAs contain transcribed 


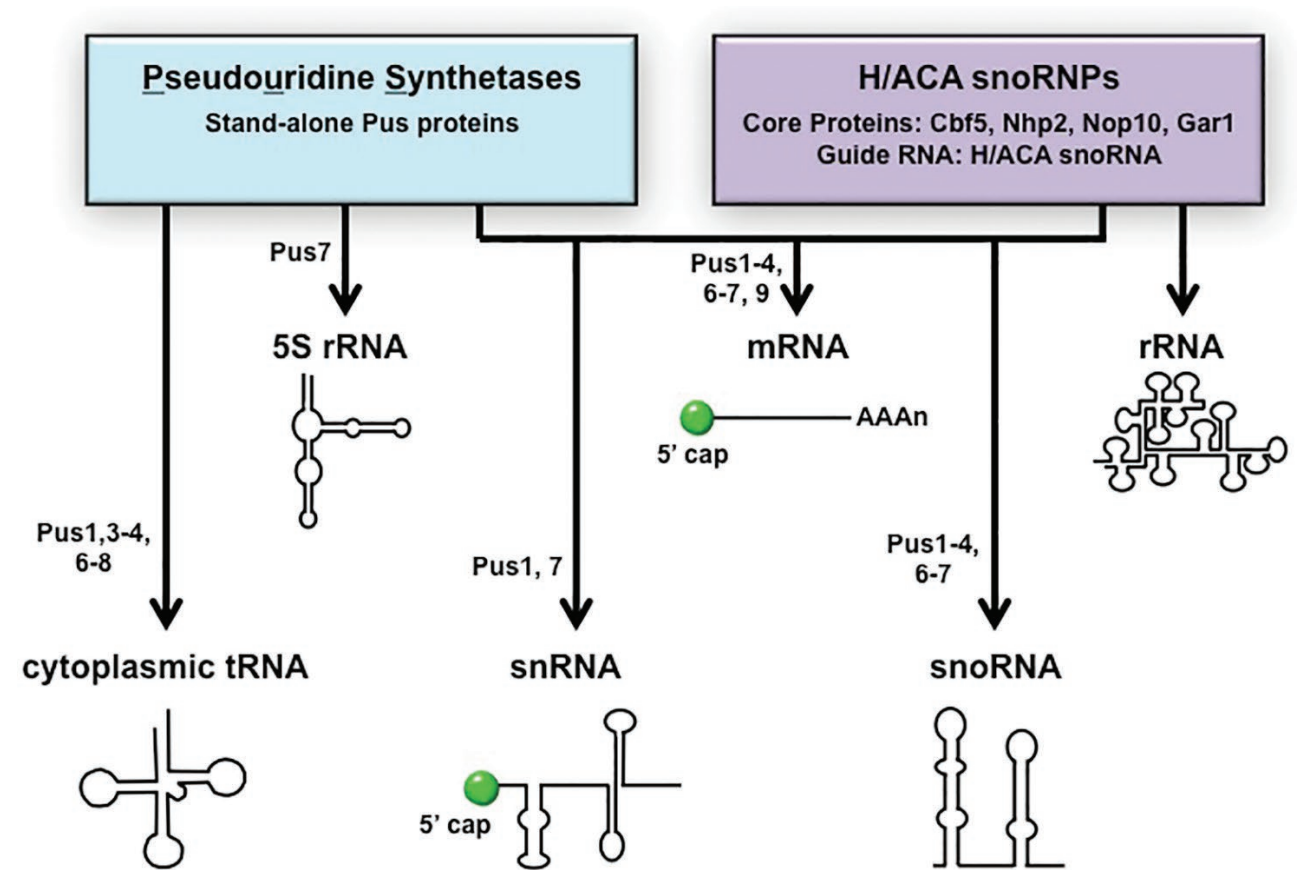

FIGURE 3 | The "tRNA" pseudouridine synthetases also modify mRNA, snRNAs, and snoRNAs. Pseudouridine modification of various RNAs is catalyzed by standalone proteins called pseudouridine synthetases (Pus) or RNPs containing guide RNAs called H/ACA snoRNPs. tRNAs and 5S RNA are pseudouridinylated solely by Pus proteins and rRNAs solely by H/ACA snoRNPs. Pseudouridine modifications of mRNA, snRNA, and snoRNA are catalyzed by either Pus proteins or H/ACA snoRNPs in a site-specific manner. The specific Pus proteins known to pseudouridinylate each RNA species are indicated. RNA substrates are not drawn to scale.

short introns, located one nucleotide $3^{\prime}$ to the anticodon, that must be removed to generate functional tRNAs. All known eukaryotic genomes encode a subset of intron-containing tRNA genes, although the percentage of such genes varies considerably (Chatterjee et al., 2018). Pre-tRNA splicing is essential in most eukaryotes because generally all reiterated copies of at least one particular isoaccepting tRNA family are encoded by introncontaining genes. The tRNA splicing process is catalyzed endonucleolytic cleavage that generates an intron and two exons, each about half the size of the mature tRNA, followed by ligation of the two resulting exons.

\section{Splicing Endonuclease Complex Cleaves mRNAs in Addition to Pre-tRNAs}

Introns in yeast and vertebrate pre-tRNAs are removed by the conserved heterotetrameric splicing endonuclease (SEN) (Trotta et al., 1997; Paushkin et al., 2004) (Figure 4). SEN is located on the cytoplasmic surface of mitochondria in budding and fission yeast, but it is in the nucleoplasm in Xenopus oocytes and HeLa cells (De Robertis et al., 1981; Yoshihisa et al., 2003, 2007; Paushkin et al., 2004; Wan and Hopper, 2018). The SEN complex fails to cleave tRNAs that possess inappropriately structured mature domains, and it will cut pre-tRNAs at inappropriate sites if the length of the anticodon stem is altered [(Reyes and Abelson, 1988) Review: (Yoshihisa, 2014)]. Although, to date, there is not a high-resolution co-structure of SEN with its pre-tRNA substrate, the data support the model that SEN interacts with the mature tRNA $3 \mathrm{~d}$ structure and it "measures" the length of the anticodon stem. Therefore, reports documenting that non-tRNAs also serve as SEN substrates were surprising. The SEN complex has been reported to cleave an mRNA that encodes the unessential cytochrome $\mathrm{b}$ mRNA processing 1 protein, Cbp1 (Tsuboi et al., 2015) (Figure 4). Moreover, other studies showed that mitochondrial-located SEN catalytic activity in budding yeast is essential even when cells generate spliced tRNAs via alternate mechanisms (Dhungel and Hopper, 2012; Cherry et al., 2018), implicating the SEN complex in processing of additional essential RNAs. However, the essential non-tRNA substrate(s) remain unknown. Thus, SEN has the capacity to cleave mRNAs and perhaps other unidentified RNAs in addition to its essential and well-studied role in catalyzing intron removal from pre-tRNAs (Figure 4).

\section{"tRNA" Splicing Ligases have mRNA Substrates}

There are two evolutionarily distinct mechanisms to ligate tRNA exons. Surprisingly, for both mechanisms, the ligase that joins pre-tRNA exons after cleavage also ligates a non-tRNA substrate. Pre-tRNA intron removal by all SEN complexes generates a $5^{\prime}$ exon bearing a $2^{\prime}, 3^{\prime}$ cyclic phosphate and a $3^{\prime}$ exon with a 5' hydroxyl (Knapp et al., 1979; Peebles et al., 1983). In yeast and plants, ligation of the two tRNA exons is catalyzed by $\mathrm{R} \lg 1 / \operatorname{Trl} 1$, that has $2^{\prime}, 3^{\prime}$ cyclic phosphodiesterase, 5' RNA kinase, and RNA ligase activities (Phizicky et al., 1986; Englert and Beier, 2005; Wang and Shuman, 2005). Ligation by Rlg1/Trl1 


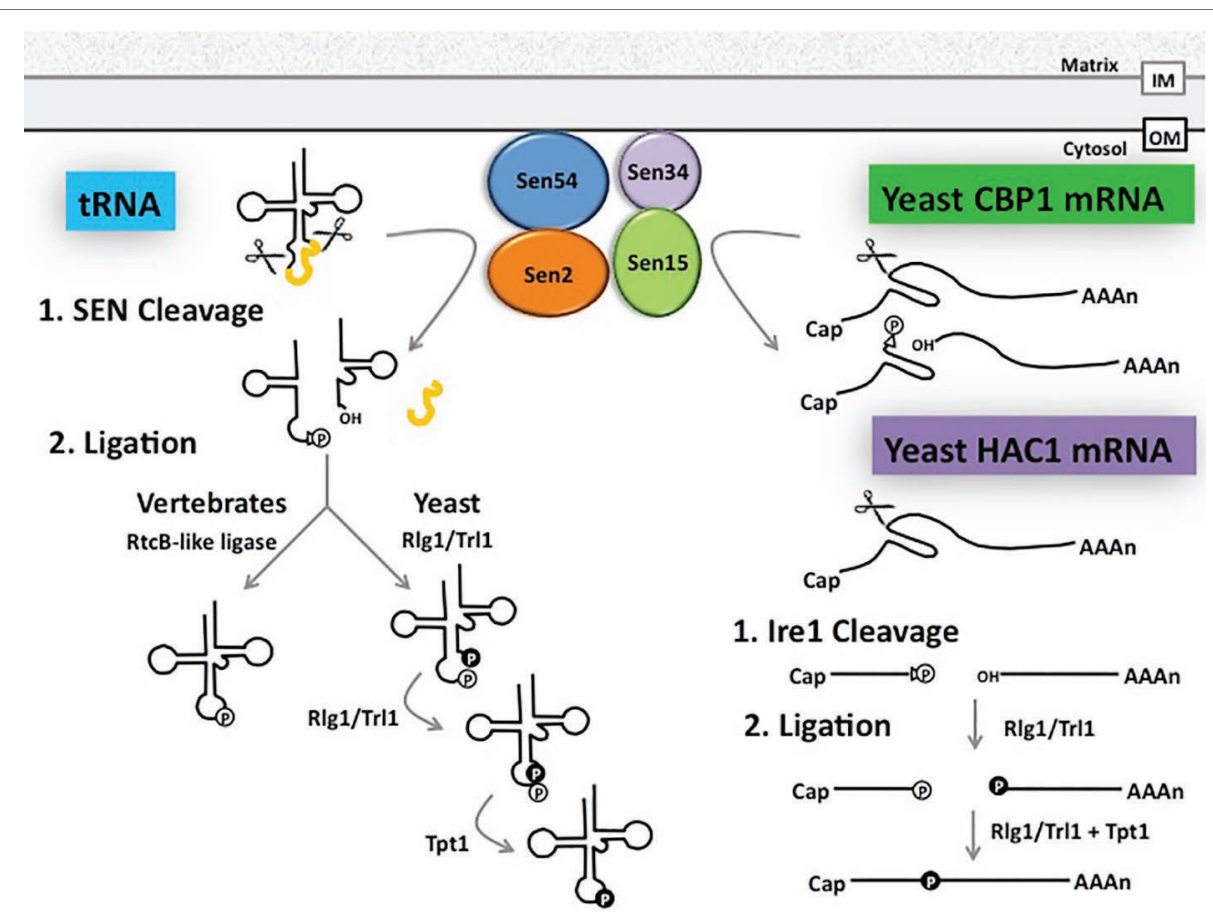

FIGURE 4 | Shared pathways for splicing and ligation of tRNA and mRNA. tRNA introns (depicted in yellow) are removed by the heterotetrameric SEN complex at the outer surface of the mitochondrial membrane in budding and fission yeast, generating a $2^{\prime}-3^{\prime}$ cyclic phosphate (triangle and "P" in white circle) at the $3^{\prime}$ end of the $5^{\prime}$ exon and a hydroxyl group at the $5^{\prime}$ end of the $3^{\prime}$ exon. In budding yeast, the tRNA $5^{\prime}$ and $3^{\prime}$ exons are ligated by Rlg1/Trl1 in the cytoplasm in a series of reactions beginning with the phosphorylation of the 5' hydroxyl group ("P" in black circle) of the $3^{\prime}$ exon and decyclization of the $2^{\prime}-3^{\prime}$ cyclic phosphate to a $2^{\prime}$ phosphate ("P" in white circle) on the $5^{\prime}$ exon. These exons are then joined using the $5^{\prime}$ phosphate, leaving the $2^{\prime}$ phosphate at the splice site to be transferred to NAD by Tpt1. In vertebrates, however, the vertebrate ligase directly joins the $2^{\prime}-3^{\prime}$ cyclic phosphate of the $5^{\prime}$ exon to the $3^{\prime}$ exon. The SEN complex also functions in the clipping of CBP1 mRNA and Rlg1/Trl1 ligates HAC1 mRNA exons generated by a protein endonuclease. Additional, but currently unidentified, RNAs are likely also processed by the SEN complex (see text). OM: Outer mitochondrial membrane, IM: Inner mitochondrial membrane.

generates a splice junction with two phosphates; the extra $2^{\prime}$ phosphate is removed via a transferase activity catalyzed by Tpt1 (Culver et al., 1997).

Although the mechanism for tRNA exon ligation is similar in budding yeast and plants (Englert and Beier, 2005), the mechanisms for tRNA ligation are different in vertebrates and archaea. In vertebrates and archaea, tRNA ligation after removal of tRNA introns is catalyzed by an enzyme complex consisting of a RtcB-like ligase (Tanaka et al., 2011), HSPC117, that catalyzes direct joining of the cleaved $5^{\prime}$ exon bearing a $3^{\prime}$ phosphate (via $2^{\prime}, 3^{\prime}$ phosphodiesterase activity of the ligase) with the $5^{\prime}$ hydroxyl on the $3^{\prime}$ exon [(Popow et al., 2011) Review: (Popow et al., 2012)] (Figure 4).

Both the Rlg1/Trl1 and the RtcB-like ligases also catalyze exon joining of a particular mRNA. Rlg1/Trl1 catalyzes ligation of HAC1 exons generated via non-conventional cleavage by an endonuclease, Ire1, rather than by the spliceosomal mechanism (Sidrauski and Walter, 1997). Cleavage of HAC1 mRNA by Ire1 generates a $5^{\prime}$ exon possessing a $2^{\prime}, 3^{\prime}$ cyclic phosphate and a $3^{\prime}$ exon possessing a $5^{\prime}$ hydroxyl. Subsequent ligation of these exons by $\mathrm{R} \lg 1 / \operatorname{Tr} 1$ is mechanistically identical to ligation of tRNA exons (Figure 4). Ligation of the exons thereby generates mature $\mathrm{HACl}$ mRNA that functions in the unfolded protein response (Sidrauski et al., 1996;
Gonzalez et al., 1999). So, the tRNA ligase, Rlg1/Trl1, is, in fact, also a ligase for HAC1 mRNA. Similarly, plant bZIP60, which also functions in the unfolded protein response, is generated by nonconventional mRNA splicing. Plant IRE endonuclease cuts pre-bZIP60, generating two exons that are subsequently ligated by tRNA ligase, RLG1 (Nagashima et al., 2016). Thus, both SEN and ligase of budding yeast and plants participate in maturation of mRNA substrates in addition to tRNA substrates.

In Xenopus oocytes and HeLa cells, pre-tRNA splicing occurs in the nucleoplasm (De Robertis et al., 1981; Lund and Dahlberg, 1998; Paushkin et al., 2004). Therefore, vertebrate SEN and HSPC117 ligase must also be located in the nucleoplasm. However, there is also a cytoplasmic pool of HSPC117/RtcB that generates a spliced mature mRNA that encodes a protein which functions in the unfolded protein response. HSPC117/ RtcB ligates XBP1 mRNA exons whose intron, like for HAC1, is removed in the cytoplasm by nuclease activity, rather than by the spliceosomal mechanism (Kosmaczewski et al., 2014). So, as for budding yeast and plants, vertebrate tRNA splicing ligase multitasks to ligate an mRNA in addition to its essential role in ligation of tRNA exons, even though the budding yeast and plant ligases are mechanistically different from the vertebrate ligase. 


\section{Multitasking Nuclear Exporters/Importers for Nuclear-Cytoplasmic Dynamics of tRNAs As Well As Other RNAs, RNPs, and Proteins}

In all eukaryotes, RNAs and proteins traffic between the nucleus and the cytoplasm. There are two distinct mechanisms by which macromolecules move between the nucleus and the cytoplasm. However, with the notable exception of most mRNAs, movement of macromolecules between the nucleus and cytoplasm generally employ the mechanism that depends upon the small GTPase, Ran, and the $\beta$-importin family of proteins [Reviews: (Gorlich and Kutay, 1999; Cook et al., 2007]. Those $\beta$-importin family members involved in import of macromolecules into the nucleus are termed importins and those functioning in export of macromolecules from the nucleus to the cytoplasm are termed exportins, although a few of the family members function both in nuclear import and export (Yoshida and Blobel, 2001; Aksu et al., 2018). The importins and exportins bind appropriate substrates, FG nuclear pore proteins, and Ran-GTP. Ran is primarily in the GTP-bound state in the nucleus and the GDP-bound state in the cytoplasm, thereby creating a Ran-GTP gradient between the nucleus and the cytoplasm. This Ran-GTP nuclear/cytoplasmic gradient determines the directionality of the movement of macromolecules between the nucleus and cytoplasm.

tRNAs move dynamically between the nucleus and the cytoplasm in yeast, protozoa, and vertebrate cells (Shaheen and Hopper, 2005; Takano et al., 2005; Shaheen et al., 2007; Huynh et al., 2010; Barhoom et al., 2011; Ohira and Suzuki, 2011; Watanabe et al., 2013; Dhakal et al., 2018; Kessler et al., 2018). Even though only a subset of eukaryotic tRNA-encoding genes contains introns, we focus on this category of tRNAs. This is because removal of introns from pre-tRNAs serves as a useful reporter for the steps of tRNA subcellular dynamics.

\section{Primary tRNA Nuclear Export}

Nuclear-cytoplasmic tRNA dynamics consists of three steps: primary nuclear export, retrograde tRNA nuclear import, and tRNA nuclear re-export (Chatterjee et al., 2018). Here, we first describe the proteins that function in primary tRNA nuclear export followed by a description of the proteins functioning in the remaining two trafficking steps (Figure 1). In budding and fission yeast, it is possible to distinguish between primary nuclear export and tRNA nuclear re-export because pre-tRNA splicing takes place on the surface of mitochondria (Yoshihisa et al., 2003, 2007; Wan and Hopper, 2018) and therefore, defects in primary nuclear export cause nuclear accumulation of unspliced pre-tRNAs. In contrast, tRNAs that have been exported to the cytoplasm via primary nuclear export and subsequently spliced prior to import back to the nucleus will accumulate spliced tRNA in the nucleus if the cells are defective in the re-export step. As detailed below, primary nuclear export and tRNA nuclear re-export can also be distinguished by assessing the status of the $\mathrm{m}^{1} \mathrm{G}_{37}$ and queuosine $\left(\mathrm{Q}_{34}\right)$ nucleoside modifications in budding yeast and T. brucei, respectively.

\section{Los1/Exportin-t/Xpot/PSD}

One member of the $\beta$-importin family, Los1 (budding yeast)/ Xpot (fission yeast)/Exportin-t (vertebrates)/PSD (plants), is dedicated to tRNA nuclear export (Hellmuth et al., 1998; Kutay et al., 1998; Sarkar and Hopper, 1998; Arts et al., 1998a). Los1/Exportin-t binds both intron-containing and intron-lacking tRNAs in a Ran-GTP-dependent fashion, and it does not require protein adaptors (Arts et al., 1998b; Lipowsky et al., 1999; Cook et al., 2009; Huang and Hopper, 2015). No other cellular RNAs have been reported to interact with Los1 or its various homologues. So, unlike the other proteins described in this review, it appears that Los1 and its homologues do not multitask in nuclear export of other RNAs or proteins (Figure 5).

Los1/Exportin-t is unessential in every tested organism, including budding yeast, fission yeast, plants, and haploid human cancer cells (Hurt et al., 1987; Hunter et al., 2003; Cherkasova et al., 2012; Blomen et al., 2015; Hart et al., 2015; Wang et al., 2015). Moreover, insects lack an Exportin-t homologue (Lippai et al., 2000). Since tRNAs must be efficiently delivered to the cytoplasm for their essential role in protein synthesis, other export pathways also function in tRNA nuclear export. Genome-wide studies with budding yeast identified candidate proteins that function in primary tRNA nuclear export (Wu et al., 2015): Crm1 (yeast)/Exportin 1 or Xpo1 (vertebrates) (Wu et al., 2015) and Mex67-Mtr2 (yeast)/NXF1NXT1 or TAP-p15 (metazoans) (Wu et al., 2015; Chatterjee et al., 2017, 2018).

\section{Crm1/Exportin-1 - A $\beta$-Importin That Functions in Nuclear Export of A Variety of Macromolecules}

The $\beta$-importin family member Crm1/Exportin-1 functions in nuclear export of proteins possessing leucine-rich nuclear export sequences (NES) (Fischer et al., 1995; Wen et al., 1995). Crm1 also functions in nuclear export of several types of RNA via interactions with adaptor proteins possessing the leucine-rich NES. In budding yeast, Crm1 mediates nuclear export of the large and small precursor ribosomal subunits [(Sengupta et al., 2010) Reviews: (Okamura et al., 2015; Chaker-Margot, 2018)], the RNA subunit of signal recognition particle (SRP) (but not in vertebrate cells) (Grosshans et al., 2001; Takeiwa et al., 2015), and TLC1, the RNA subunit of telomerase [(Gallardo et al., 2008) Review: (Vasianovich and Wellinger, 2017)], via interactions of the cargo RNA/RNPs with adaptor proteins containing the leucine rich motif (Figure 5). In vertebrate cells, Exportin-1 also functions in nuclear export of snRNAs and particular mRNAs involved in stress and particular viral RNAs [Reviews: (Kohler and Hurt, 2007; Delaleau and Borden, 2015)].

$\mathrm{Crm} 1$ is also implicated in primary tRNA nuclear export because yeast cells possessing a temperature sensitive (ts) mutation of CRM1 accumulate unspliced tRNA at the nuclear rim at the non-permissive temperature ( $\mathrm{Wu}$ et al., 2015). Furthermore, Crm1 and Los1 genetically interact as $\mathrm{crm} 1-1$ los $1 \Delta$ double mutants have synthetic growth defects (Wu et al., 2015). However, to date, there are no publications that document direct interactions between Crm1 and intron-containing tRNA; thus, Crm1 could mediate primary tRNA nuclear export 


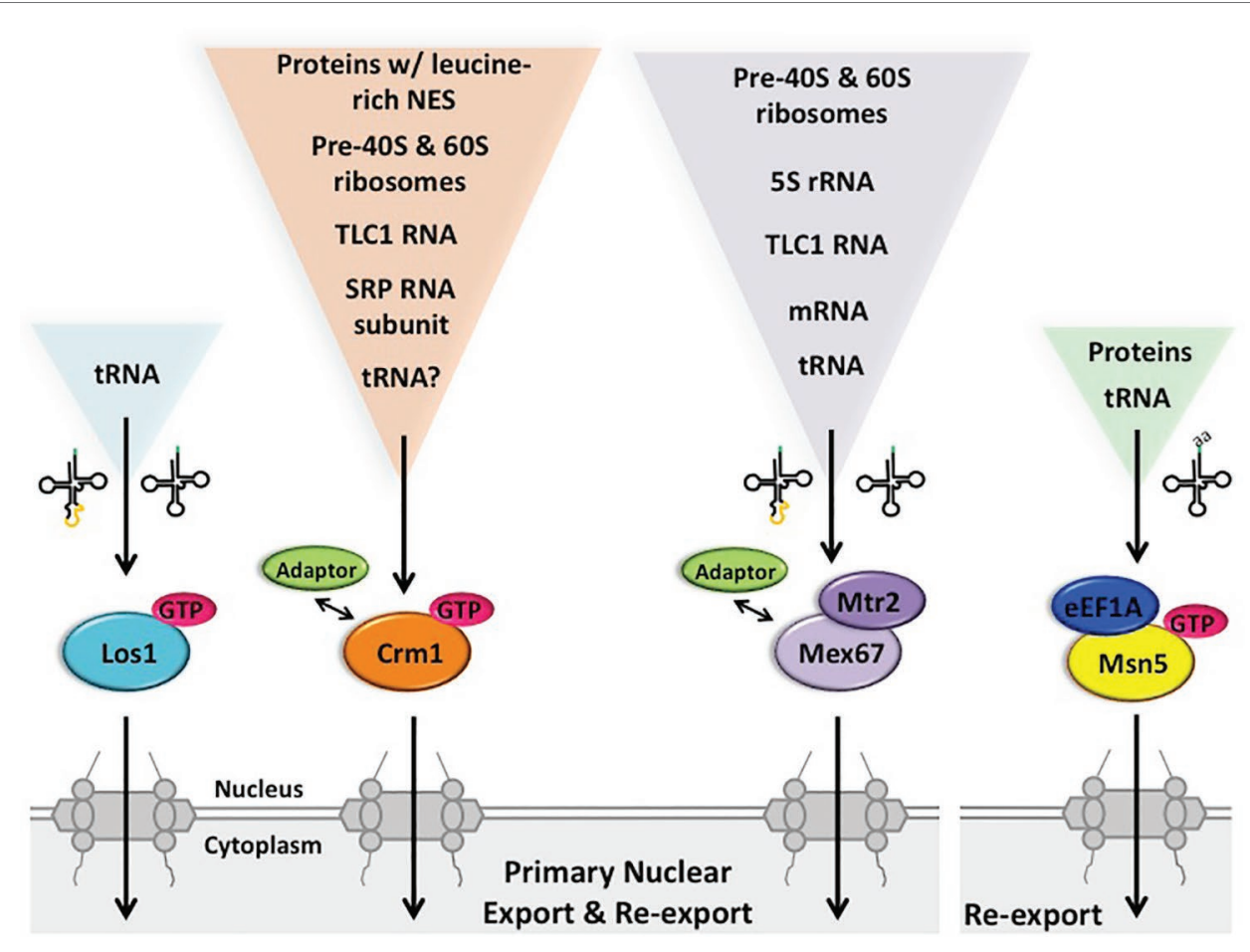

FIGURE 5 | The multiple pathways for budding yeast primary tRNA nuclear export and re-export are also utilized for the export of other RNA and protein species. Primary export and re-export of tRNAs from the nucleus to the cytoplasm occurs via Ran-dependent and Ran-independent exporters, specifically Los1, Mex67Mtr2 and possibly Crm1 (left), which interact with both spliced and unspliced tRNAs. Msn5, however, selectively re-exports charged tRNAs, forming a quaternary complex with Ran-GTP and eEF1A (right). Although Los1 is a dedicated tRNA nuclear exporter, Mex67-Mtr2, Msn5 and Crm1 can export various RNA and/or protein species with the assistance of different adaptor proteins. GTP, Ran-GTP; SRP, signal recognition particle; NES, nuclear export sequence.

indirectly. In summary, the exportin Crm1 is involved in nuclear export of numerous RNAs and RNPs, and perhaps also pre-tRNA nuclear export (Figure 5).

\section{Mex67-Mtr2/NXF1-NXT1-A Ran-GTP Independent Mechanism for Nuclear Export of Numerous RNAs}

Although it is well established that nuclear export of small structured RNAs like tRNAs, snRNAs, SRP RNA, and TLC1 as well as ribosomal subunits employ one or more members of the $\beta$-importin family, nuclear export of mRNAs is largely independent of the Ran-GTP mechanism [Reviews: (Kelly and Corbett, 2009; Okamura et al., 2015)]. Instead, mRNA nuclear export occurs via sequential rearrangements of multiprotein RNA-binding complexes. In metazoan cells, a transcriptiondependent protein complex, TREX, is recruited near mRNA 5' caps via interaction with the cap-binding complex and then a heterodimer, NXF1-NXT1 (TAP-p15) is recruited before nuclear export proceeds. The yeast heterodimeric homologue, Mex67-Mtr2, appears to interact with mRNAs via a transcriptiondependent $3^{\prime}$ end processing mechanism using several protein adaptors (Kelly and Corbett, 2009). The Mex67-Mtr2 heterodimer and the metazoan homologues also function in nuclear export of other RNAs (Figure 5). They function in nuclear export of 5S rRNA (Yao et al., 2007), the pre-60S ribosome (Yao et al., 2007), the pre-40S ribosome (Faza et al., 2012), TLC1
RNA (Wu et al., 2014), and, in vertebrates, type D unspliced retroviral RNAs (Ernst et al., 1997; Pasquinelli et al., 1997).

Recently, Mex67-Mtr2 in budding yeast has been shown to export tRNAs to the cytoplasm (Chatterjee et al., 2017). Incubation of yeast harboring temperature-sensitive mutations of the essential MEX67 and MTR2 genes at a non-permissive temperature results in nuclear accumulation of end-processed, intron-containing tRNAs, similar to the phenotype of yeast lacking LOS1 (Wu et al., 2015; Chatterjee et al., 2017). Moreover, providing yeast cells lacking Los1 ( $\beta$-importin) with a mere fivefold excess of ectopic Mex67-Mtr2 results in efficient suppression of both phenotypes of los $1 \Delta$-accumulation of unspliced tRNAs and accumulation of tRNA in nuclei (Chatterjee et al., 2017). So, Mex67-Mtr2 is able to substitute for Los1, if cells are provided with sufficient quantities of the heterodimer. In vivo biochemical studies documented that protein A-tagged Mex67 co-purifies with intron-containing pre-tRNA as well as spliced tRNA (Chatterjee et al., 2017). The data support the model that Mex67-Mtr2 functions directly in tRNA nuclear export in both the primary and the re-export steps. It is unknown whether vertebrate cells employ Mex67-Mtr2 for tRNA nuclear export. However, NXT1 has been reported to stimulate nuclear tRNA export in permeabilized HeLa cells (Ossareh-Nazari et al., 2000) (Figure 5).

How Mex67-Mtr2 interacts with tRNAs remains unknown as none of the previously described Mex67-Mtr2 adaptors were 
uncovered in the genome-wide screen for tRNA splicing defects (Kelly and Corbett, 2009; Wu et al., 2015). Therefore, if Mex67-Mtr2 interaction with tRNA occurs via an adaptor, the adaptor may be encoded by redundant genes or it may be novel. It is also feasible that Mex67-Mtr2 interacts with tRNAs without employing an adaptor, similar to reported interactions of NXF1NXT1 with particular heat shock mRNAs (Zander et al., 2016). It is also unknown what tRNA structures are important for interaction with Mex67-Mtr2.

In summary, there are at least two (i.e., Los1 and Mex67-Mtr2) and perhaps three (i.e., Crm1) or more, pathways in budding yeast for primary tRNA nuclear export. Both Mex67-Mtr2 and Crm1 are involved in the nuclear export of numerous other RNAs; so, unlike Los1, they are not dedicated to tRNA nuclear export (Figure 5). It will be interesting to learn whether they have the same fidelity for exporting tRNAs that are appropriately structured and processed to the cytoplasm as does Los1.

\section{Retrograde tRNA Nuclear Import}

The quandary that the budding yeast SEN complex is located on the surface of mitochondria but spliced tRNAs accumulate in the nucleus under particular stress conditions (Sarkar and Hopper, 1998; Grosshans et al., 2000; Azad et al., 2001; Feng and Hopper, 2002; Takano et al., 2005) led the Hopper and Yoshihisa labs to consider the unorthodox possibility that tRNAs in the cytoplasm could travel in a retrograde direction back to the nucleus. Employing RNA florescence in situ hybridization (FISH), these labs demonstrated that ectopic "foreign" tRNAs encoded by one nucleus of a heterokaryon could travel to and accumulate in the nucleus that did not encode the tRNA (Shaheen and Hopper, 2005; Takano et al., 2005), providing strong evidence for tRNA retrograde nuclear import (Figure 1). Other studies of haploid yeast and rat hepatoma cells in culture showed that tRNAs accumulate in nuclei upon nutrient deprivation even when transcription of new tRNAs is inhibited by thiolutin or actinomycin D, respectively (Takano et al., 2005; Shaheen et al., 2007; Whitney et al., 2007). Employing nuclear import assays with permeabilized HeLa cells, the Fassati group demonstrated that tRNA nuclear import occurs in vertebrate cells and their studies also showed that $\mathrm{tRNA}$ retrograde traffic provides one mechanism by which the retrotranscribed HIV genome can access the nuclear interior in nondividing cells (Zaitseva et al., 2006). Subsequent RNA FISH studies in protozoa, brine shrimp, and vertebrate cells in culture, and, most recently, tagged-tRNAs injected into vertebrate live cells, demonstrate widespread conservation of nuclear import of cytoplasmic tRNAs, especially in response to nutrient and/or heat stress [(Huynh et al., 2010; Barhoom et al., 2011; Miyagawa et al., 2012; Watanabe et al., 2013; Chen et al., 2016; Dhakal et al., 2018) Review: (Huang and Hopper, 2016)].

The mechanism of tRNA retrograde nuclear import remains poorly understood. However, it is thought that tRNA retrograde nuclear import occurs constitutively as well as being upregulated in response to stress (Chatterjee et al., 2018). As detailed below, since $\mathrm{m}^{1} \mathrm{G}_{37}$ modification of several budding yeast tRNAs that are encoded by intron-containing genes require tRNA retrograde nuclear import, retrograde tRNA nuclear import must occur constitutively to generate functional tRNAs for protein synthesis (Figure 1). However, as accumulation of nuclear pools of tRNA from the cytoplasm also occurs upon stress conditions, the import process may also be inducible (Shaheen and Hopper, 2005; Takano et al., 2005, 2015; Hurto et al., 2007; Shaheen et al., 2007; Whitney et al., 2007). Two proteins from budding yeast have been identified as possible tRNA nuclear importers, Mtr10 (Shaheen and Hopper, 2005; Murthi et al., 2010) and Ssa2 (Takano et al., 2015); the latter is more likely to participate in regulated retrograde tRNA nuclear import (Figure 6).

\section{Mtr10-A Ran-GTP Dependent Importer May Function in tRNA Nuclear Import}

Budding yeast Mtr10 is a $\beta$-importin family member best characterized for its role in nuclear import of the protein Npl3 that is required for mRNA nuclear export (Senger et al., 1998). Mtr10 is also implicated in nuclear import of the TLC1 RNA subunit of telomerase that shuttles between the nucleus and the cytoplasm; cells lacking MTR10 (mtr10A) have short telomeres, the levels of TLC1 are reduced and TLC1 does not normally accumulate in the nucleus. However, it is unknown whether Mtr10 is directly involved in TLC1 nuclear import (Ferrezuelo et al., 2002; Gallardo et al., 2008).

Three lines of evidence suggested that Mtr10 functions in tRNA retrograde nuclear import. First, tRNA nuclear import was reported to be dependent upon the Ran-GTP gradient, although this conclusion has been controversial (Shaheen and

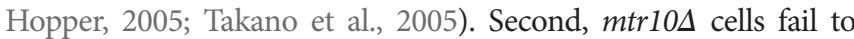
accumulate tRNA in the nucleus upon amino acid (aa) deprivation, in contrast to wild-type cells (Shaheen and Hopper, 2005). Third, mtr10s los1s mutants do not accumulate large nuclear pools of tRNAs (Murthi et al., 2010); as the level of nuclear accumulation in los $1 \Delta$ cells is the result of defects in both tRNA primary nuclear export and re-export, reduced tRNA nuclear pools in

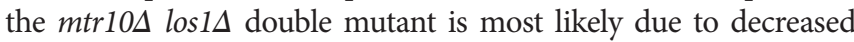
import of tRNA from the cytoplasm. Despite these three lines of evidence, Mtr10 did not co-purify with tRNA under conditions in which Npl3 and Mtr10 interaction was readily detected (Huang and Hopper, 2015). Therefore, Mtr10 may affect tRNA nuclear pools indirectly. In vertebrate cells, the putative Mtr10 orthologue, TNPO3 (Transportin 3) serves to import serine-arginine-rich splicing factors into the nucleus (Maertens et al., 2014). No apparent role for TNPO3 in tRNA nuclear import has been detected; instead, it has been proposed that TNPO3 functions in disassembly of tRNA-capsid complexes from HIV pre-integration complexes after nuclear import (Zhou et al., 2011).

\section{Ssa2-A Protein Chaperone Implicated in Ran-GTP Independent tRNA Nuclear Import}

Takano et al. reported that retrograde tRNA nuclear import is ATP-dependent (Takano et al., 2005). Thus, to identify proteins that may participate in tRNA retrograde nuclear import, the Yoshihisa group searched for proteins from budding yeast able to bind tRNA in an ATP-sensitive fashion and thereby 


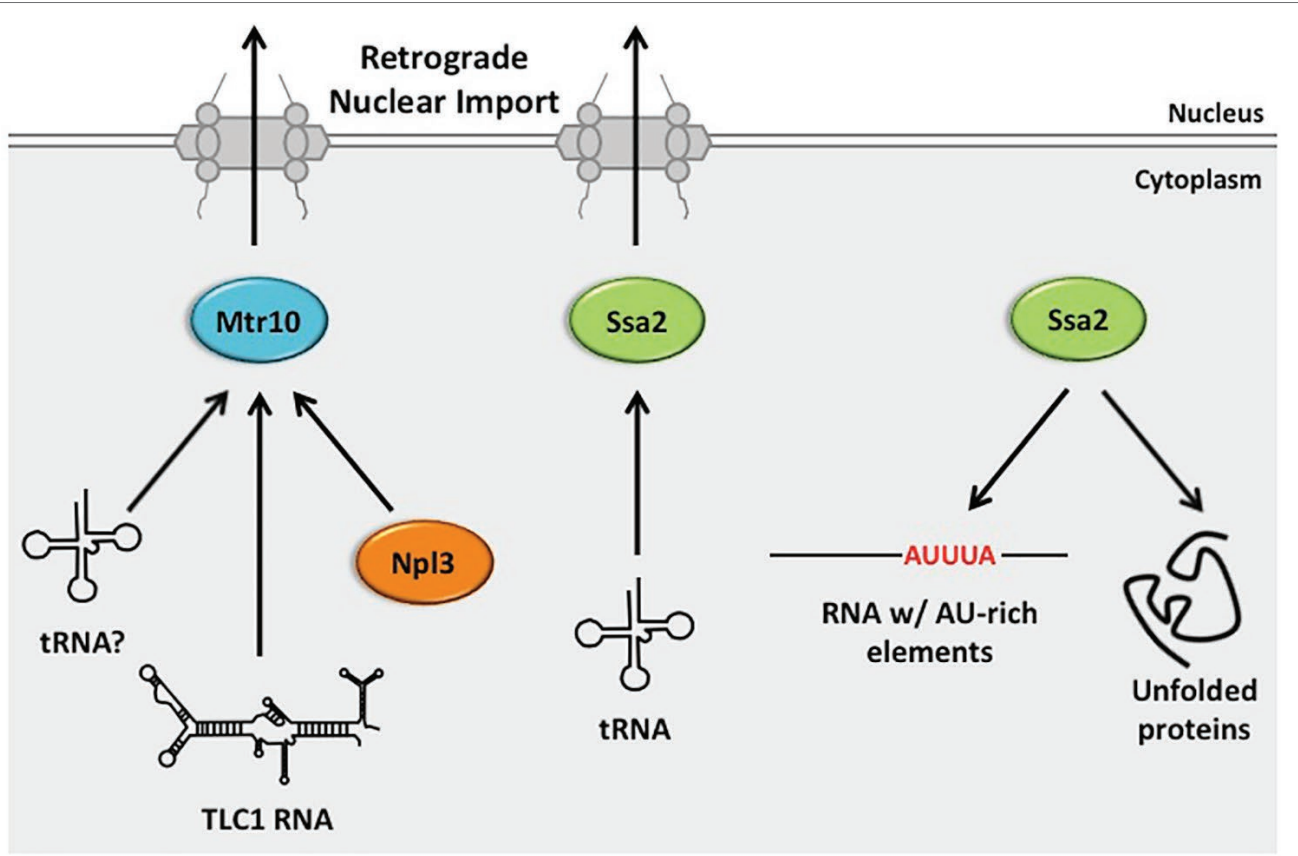

FIGURE 6 | The role of budding yeast retrograde tRNA nuclear importers in nuclear import and gene expression regulation of other RNA and proteins. Retrograde tRNA nuclear import is mediated in a Ran-GTP-dependent manner, likely by Mtr10 and a Ran-GTP-independent manner by Ssa2. Mtr10 is also an importer of nuclear export protein Npl3 and it is implicated as a nuclear importer for the TLC1 RNA of telomerase. Ssa2 has additional non-import related functions, including its well-characterized role in protein folding. Members of the Hsp70 family also bind RNAs containing AU-rich elements, leading to their degradation.

identified Ssa2. Ssa2 is a constitutively expressed chaperone and member of the heat shock protein 70 (HSP70) family with known functions in protein folding. However, members of the Hsp70 family also bind RNA AU-rich elements-sequences characteristic of unstable mRNAs (Henics et al., 1999; Takano et al., 2015) (Figure 6). Cells deleted for SSA2 (ssa2A) fail to accumulate elevated tRNA nuclear pools when cells are deprived for aa (Takano et al., 2015). The results support a role for Ssa2 in nutrient-dependent regulated tRNA nuclear import. Ssa2 prefers unmodified to fully modified tRNA and it can bind a nuclear pore protein. Thus, Ssa2 may serve as a tRNA chaperone delivering defective tRNAs to the nucleus for quality control and as a cellular response to nutrient deprivation.

ssa $2 \Delta$ cells that are also depleted for Mtr10 have significantly smaller nuclear pools of tRNA upon aa deprivation than either individual mutant, indicating that Ssa2 and Mtr10 independently affect tRNA retrograde nuclear import. The results provide evidence for both Ran-dependent and Ran-independent pathways for retrograde tRNA nuclear import and a role for each in interacting with multiple RNA and protein substrates (Figure 6).

\section{tRNA Re-export From the Nucleus to the Cytoplasm}

Data from budding yeast document that tRNAs imported from the cytoplasm to the nucleus via retrograde tRNA nuclear import are re-exported to the cytoplasm, provided that cells are provided with ample nutrients. First, cells acutely deprived of aa, glucose, or phosphate accumulate tRNAs in the nucleus;
tRNA nuclear accumulation is not due to defects in primary tRNA nuclear export because the tRNAs are efficiently spliced under these conditions (Shaheen and Hopper, 2005; Hurto et al., 2007; Whitney et al., 2007; Huang and Hopper, 2014). Upon re-feeding with the appropriate nutrient, the tRNA nuclear pools rapidly dissipate (Whitney et al., 2007). Similarly, tRNA nuclear accumulation occurs in rat hepatoma cells upon aa deprivation, and upon re-feeding, there is rapid movement of the tRNAs to the cytoplasm (Shaheen et al., 2007).

Second, wybutosine ( $\mathrm{yW}$ ) modification of $\mathrm{G}_{37}$ of budding yeast tRNA ${ }^{\text {Phe }}$ requires both the primary tRNA nuclear export and re-export steps (Ohira and Suzuki, 2011). This is because the first step of $\mathrm{yW}$ modification is catalyzed by the Trm5 methyltransferase that acts only on spliced tRNAs but is located in the nucleus; so, tRNA ${ }^{\text {Phe }}$ must first be exported to the cytoplasm by the primary tRNA nuclear export process to be spliced on the surface of mitochondria and then imported back into the nucleus to gain $\mathrm{m}^{1} \mathrm{G}_{37}$, catalyzed by Trm5. The subsequent steps of $\mathrm{yW}$ modification are catalyzed by cytoplasmic enzymes and therefore to complete $y \mathrm{~W}$ modification, $\mathrm{m}^{1} \mathrm{G}_{37}$ modified $\mathrm{tRNA} \mathrm{A}^{\text {Phe }}$ must be re-exported to the cytoplasm (Ohira and Suzuki, 2011) (Figure 1). Similarly, queuosine $(\mathrm{Q})$ modification of tRNA ${ }^{\mathrm{Tyr}}$ in T. brucei requires that the pre-tRNA $A^{\mathrm{Tyr}}$ be exported to the cytoplasm where its intron is removed; following import to the nucleus, the spliced tRNA is modified by nucleus-located tRNAguanine transglycosylase, which has specificity for spliced tRNA ${ }^{\text {Tyr }}$. Q-modified tRNA ${ }^{\text {Tyr }}$ is then re-exported to the cytoplasm to fulfill its function in protein synthesis (Kessler et al., 2018). 
Which exporters function in the tRNA re-export step? Evidence supports the model that Los1 and Mex67-Mtr2 that function in primary tRNA nuclear export, also function in tRNA re-export to the cytoplasm. As detailed above, the vertebrate and $S$. pombe Los1 homologues, Exportin-t and Xpot, are able to bind both intron-containing and mature tRNA; similarly in budding yeast, both unspliced and spliced tRNAs co-purify with Los1 (Huang and Hopper, 2015). Therefore, Los1 also serves in the re-export step to deliver spliced tRNA to the cytoplasm. Likewise, Mex67 co-purifies with spliced tRNA (Chatterjee et al., 2017), and therefore, it is likely to also function in tRNA nuclear re-export in budding yeast (Figure 5). In addition to Los1/Exportin-t and Mex67-Mtr2/NXF1-NXT1, another protein, Msn5/Exportin-5, functions in tRNA nuclear re-export.

\section{Msn5/Exportin-5 - A $\beta$-importin That Participates in tRNA Nuclear Export in Yeast and Vertebrates}

Yeast Msn5 and its exportin-5 vertebrate homologue have been shown to function in tRNA nuclear export. However, this $\beta$-importin family member serves additional roles in nuclearcytoplasmic dynamics. Vertebrate and plant Msn5 homologues, Exportin-5 and Hasty (HST), respectively, serve to export pre-micro RNA (miRNA) from the nucleus to the cytoplasm (Yi et al., 2003; Bohnsack et al., 2004; Lund et al., 2004; Park et al., 2005; Kim et al., 2016). This is accomplished by direct binding of Exportin-t/HST to the hairpin structure of miRNAs and other RNAs (Shibata et al., 2006). In addition, vertebrate Exportin-5 functions in SRP RNA (Takeiwa et al., 2015) and adenoviral VA1 RNA (Gwizdek et al., 2003) nuclear export. Budding yeast Msn5 functions to export numerous proteins to the cytoplasm. These include the HO protein, that is required for mating type switching, and phosphorylated forms of transcription factors Pho4, Mig1, Crz1, and Maf1 that travel to the cytoplasm in response to various environmental conditions [Reviews: (Hopper, 1999; Ciesla and Boguta, 2008)]. Furthermore, the interaction between Msn5 and phosphorylated Pho4 and a peptide from $\mathrm{HO}$ are direct because binding occurs in vitro with purified components in the presence of Ran-GTP (Kaffman et al., 1998; Bakhrat et al., 2008) (Figure 5). There is no evidence showing binding of vertebrate Exportin-5 with proteins.

tRNAs have been shown to be aminoacylated in the nucleus in both vertebrate cells and budding yeast (Lund and Dahlberg, 1998; Sarkar et al., 1999; Grosshans et al., 2000; Azad et al., 2001), even though the vast majority of the aminoacyl tRNA synthetases reside and function in the cytoplasm for protein synthesis. Both in cultured vertebrate cells and in Xenopus oocytes, Exportin-5 was shown to promote nuclear export of aminoacylated tRNA (aa-tRNA) via a complex with translation elongation factor $1 \mathrm{~A}$ (eEF1A) in a Ran-GTPdependent mechanism (Bohnsack et al., 2002; Calado et al., 2002). The authors proposed that a major role for Exportin-5 in vertebrate cells is to prevent translation factors from accumulating in the nucleus. More recent studies document that SNAG-containing transcription factors can piggyback on the Exportin-5-aa-tRNA-eEF1A complex via eEF1A interaction so to provide a mechanism for nuclear export of this category of proteins (Mingot et al., 2013). Plant HST has no apparent role in tRNA nuclear export (Park et al., 2005).

The role of Msn5 in tRNA nuclear export in budding yeast was first demonstrated by FISH studies documenting tRNA nuclear accumulation in $m s n 5 \Delta$ cells deprived for aa (Shaheen and Hopper, 2005; Murthi et al., 2010). However, as there is no defect in pre-tRNA splicing in $m s n 5 \Delta$ cells, it was concluded that Msn5 does not participate in primary nuclear export for the 10 families of tRNAs that are encoded by intron-containing genes in budding yeast, but rather that Msn5 is dedicated to their tRNA nuclear re-export (Murthi et al., 2010). Studies to capture in vivo Msn5 with its tRNA cargo provide strong evidence that in a Ran-GTP-dependent mechanism, Msn5 interacts efficiently with spliced tRNA, but interacts very inefficiently with intron-containing tRNA (Huang and Hopper, 2015), supporting the selective role for Msn5 in the re-export of tRNAs encoded by intron-containing genes. Msn5 preferentially binds aa-tRNA in a quaternary complex with eEF1A and Ran-GTP (Figure 5).

The manner in which Msn5 assembles into a tRNA nuclear export complex provides explanations for earlier studies demonstrating roles for eEF1A, nuclear pools of aminoacyl synthetases, and the enzyme that adds CCA to tRNA $3^{\prime}$ termini (Cca1) in tRNA nuclear export (Sarkar et al., 1999; Grosshans et al., 2000; Azad et al., 2001; Feng and Hopper, 2002). Msn5 provides one mechanism for cells to regulate tRNA re-export in response to aa deprivation; it also serves to regulate the nuclear-cytoplasmic distribution of several transcription factors in response to environmental stress.

In summary, re-export of tRNAs in budding yeast employs at least three nuclear exporters: Los1, Mex67-Mtr2, and Msn5 (Figure 5). As Msn5 does not interact with intron-containing tRNA, it functions solely in the re-export step for the category of tRNAs encoded by intron-containing genes. As for the other transporters discussed, Msn5 has multiple different non-tRNA substrates and multitasks in their nuclear export.

\section{Function of RNA Subcellular Dynamics Between the Nucleus, Cytoplasm, and Mitochondria}

Although discovery of the tRNA retrograde pathway was surprising and initially counter intuitive, subsequent studies document multiple functions for this complicated subcellular tRNA traffic. In budding yeast, tRNA retrograde dynamics function in translation for a subset of proteins (Chu and Hopper, 2013), in quality control of tRNA $5^{\prime}$ leader processing and modification [(Kramer and Hopper, 2013) Review: (Huang and Hopper, 2016)], and in addition of a particular tRNA nucleoside modification (Ohira and Suzuki, 2011). Other small RNAs, in particular, snRNA and TLC1 RNA, also shuttle between the nucleus to the cytoplasm and have been shown to have their processing steps occur both in the nucleus and the cytoplasm. So, RNA trafficking between the nucleus and the cytoplasm is not unique to tRNA. Furthermore, RNA processing on the surface of mitochondria is not restricted to pre-tRNA splicing (Chatterjee et al., 2018). In budding yeast cyclization of $t^{6} \mathrm{~A}_{37}$ to $\mathrm{ct}^{6} \mathrm{~A}_{37}$ is catalyzed by $\mathrm{Tcd} 1$ and $\mathrm{Tcd} 2$ which are also located 
on the mitochondrial surface (Huh et al., 2003; Miyauchi et al., 2013). Likewise, $Q_{34}$ tRNA modification catalyzed by the heteromeric transglycosylase in mouse occurs on the mitochondrial surface (Boland et al., 2009). Nor is RNA processing on mitochondria restricted to tRNA as the maturation of nucleases that catalyze processing of piRNA (PIWI-interacting RNA), 5' Zucchini (MitoPLD) and/or 3' trimmer (PARN-1), in mouse (Watanabe et al., 2011), flies (Huang et al., 2011), silk worm (Izumi et al., 2016) and C. elegans (Tang et al., 2016) reside on the mitochondrial cytoplasmic surface. Studies in budding and fission yeast documented a role for Tom70, a protein subunit of the TOM mitochondrial import complex, in localizing the SEN subunits to mitochondria (Wan and Hopper, 2018). It will be interesting to learn if Tom70 homologues in metazoans function to localize the other yeast and metazoan RNA processing enzymes to mitochondria.

\section{EPILOGUE}

In stark contrast to the commonly held notion that separate gene products and mechanisms are employed to process different categories of RNAs, there are numerous examples of gene products or complexes involved in tRNA biology that multitask in the production and/or subcellular trafficking of other RNAs. Such multitasking likely arose as mechanisms for cells to streamline their genomes by having given gene products serve multiple tasks. There are other mechanisms in eukaryotic RNA biology that also have been selected to streamline genomes. For example, due to alternative starts of transcription and/or alternate translation starts, single genes encoding tRNA modification enzymes and aminoacyl synthetases generate multiple proteins with distinct subcellular

\section{REFERENCES}

Aksu, M., Pleiner, T., Karaca, S., Kappert, C., Dehne, H. J., Seibel, K., et al. (2018). Xpo7 is a broad-spectrum exportin and a nuclear import receptor. J. Cell Biol. 217, 2329-2340. doi: 10.1083/jcb.201712013

Arts, G. J., Fornerod, M., and Mattaj, I. W. (1998a). Identification of a nuclear export receptor for tRNA. Curr. Biol. 8, 305-314.

Arts, G. J., Kuersten, S., Romby, P., Ehresmann, B., and Mattaj, I. W. (1998b). The role of exportin-t in selective nuclear export of mature tRNAs. EMBO J. 17, 7430-7441.

Azad, A. K., Stanford, D. R., Sarkar, S., and Hopper, A. K. (2001). Role of nuclear pools of aminoacyl-tRNA synthetases in tRNA nuclear export. Mol. Biol. Cell 12, 1381-1392.

Bakhrat, A., Baranes-Bachar, K., Reshef, D., Voloshin, O., Krichevsky, O., and Raveh, D. (2008). Nuclear export of Ho endonuclease of yeast via Msn5. Curr. Genet. 54, 271-281. doi: 10.1007/s00294-008-0216-8

Barhoom, S., Kaur, J., Cooperman, B. S., Smorodinsky, N. I., Smilansky, Z., Ehrlich, M., et al. (2011). Quantitative single cell monitoring of protein synthesis at subcellular resolution using fluorescently labeled tRNA. Nucleic Acids Res. 39:e129. doi: 10.1093/nar/gkr601

Benko, A. L., Vaduva, G., Martin, N. C., and Hopper, A. K. (2000). Competition between a sterol biosynthetic enzyme and tRNA modification in addition to changes in the protein synthesis machinery causes altered nonsense suppression. Proc. Natl. Acad. Sci. U. S. A. 97, 61-66.

Bentley, D. L. (2014). Coupling mRNA processing with transcription in time and space. Nat. Rev. Genet. 15, 163-175. doi: 10.1038/nrg3662 locations so to deliver the same catalytic activities to separate destinations; for example, TRM1 encodes two proteins, one targeted to mitochondria and the other to the nucleus and CCA1 encodes three proteins that are targeted to the mitochondria, nucleus, or the cytoplasm [Reviews: (Martin and Hopper, 1994; Danpure, 1995)]. Moreover, some proteins in tRNA biology serve additional unrelated roles. For example, budding yeast Mod5 that catalyzes modification of $\mathrm{A}_{37}$ to $\mathrm{i}^{6} \mathrm{~A}_{37}$ of particular tRNAs also functions in regulation of sterol biogenesis in the cytoplasm (Benko et al., 2000) and transcription silencing in the nucleus (Pratt-Hyatt et al., 2013) and numerous budding yeast and vertebrate tRNA aminoacyl synthetases possess functions independent of translation [Reviews: (Guo and Schimmel, 2013; Yakobov et al., 2018)]. Further exploration will undoubtedly uncover new examples of multitasking in the eukaryotic world of tRNA biology.

\section{AUTHOR CONTRIBUTIONS}

$\mathrm{AH}$ and $\mathrm{RN}$ each participated in the preparation of this review.

\section{FUNDING}

The work from the $\mathrm{AH}$ lab is supported by a grant from the National Institutions of Health \#122884.

\section{ACKNOWLEDGMENTS}

The authors thank Dr. Kunal Chatterjee for insightful comments on drafts of this article.

Blomen, V. A., Majek, P., Jae, L. T., Bigenzahn, J. W., Nieuwenhuis, J., Staring, J., et al. (2015). Gene essentiality and synthetic lethality in haploid human cells. Science 350, 1092-1096. doi: 10.1126/science.aac7557

Bohnsack, M. T., Czaplinski, K., and Gorlich, D. (2004). Exportin 5 is a RanGTP-dependent dsRNA-binding protein that mediates nuclear export of pre-miRNAs. RNA 10, 185-191. doi: 10.1261/rna.5167604

Bohnsack, M. T., Regener, K., Schwappach, B., Saffrich, R., Paraskeva, E., Hartmann, E., et al. (2002). Exp5 exports eEF1A via tRNA from nuclei and synergizes with other transport pathways to confine translation to the cytoplasm. EMBO J. 21, 6205-6215. doi: 10.1093/emboj/cdf613

Boland, C., Hayes, P., Santa-Maria, I., Nishimura, S., and Kelly, V. P. (2009). Queuosine formation in eukaryotic tRNA occurs via a mitochondria-localized heteromeric transglycosylase. J. Biol. Chem. 284, 18218-18227. doi: 10.1074/ jbc.M109.002477

Calado, A., Treichel, N., Muller, E. C., Otto, A., and Kutay, U. (2002). Exportin-5mediated nuclear export of eukaryotic elongation factor 1A and tRNA. EMBO J. 21, 6216-6224. doi: 10.1093/emboj/cdf620

Carlile, T. M., Rojas-Duran, M. F., Zinshteyn, B., Shin, H., Bartoli, K. M., and Gilbert, W. V. (2014). Pseudouridine profiling reveals regulated mRNA pseudouridylation in yeast and human cells. Nature 515, 143-146. doi: $10.1038 /$ nature 13802

Chaker-Margot, M. (2018). Assembly of the small ribosomal subunit in yeast: mechanism and regulation. RNA 24, 881-891. doi: 10.1261/rna.066985.118

Chatterjee, K., Majumder, S., Wan, Y., Shah, V., Wu, J., and Huang, H. Y. (2017). Sharing the load: Mex67-Mtr2 cofunctions with Los1 in primary tRNA nuclear export. Genes Dev. 31, 2186-2198. doi: 10.1101/gad.305904.117 
Chatterjee, K., Nostramo, R. T., Wan, Y., and Hopper, A. K. (2018). tRNA dynamics between the nucleus, cytoplasm and mitochondrial surface: location, location, location. Biochim. Biophys. Acta Gene Regul. Mech. 1861, 373-386. doi: 10.1016/j.bbagrm.2017.11.007

Chen, D. F., Lin, C., Wang, H. L., Zhang, L., Dai, L., Jia, S. N., et al. (2016). An La-related protein controls cell cycle arrest by nuclear retrograde transport of tRNAs during diapause formation in Artemia. BMC Biol. 14:16. doi: 10.1186/s12915-016-0239-4

Cherkasova, V., Maury, L. L., Bacikova, D., Pridham, K., Bahler, J., and Maraia, R. J. (2012). Altered nuclear tRNA metabolism in La-deleted Schizosaccharomyces pombe is accompanied by a nutritional stress response involving Atf1p and Pcrlp that is suppressible by Xpo-t/Los1p. Mol. Biol. Cell 23, 480-491.

Cherry, P. D., White, L. K., York, K., and Hesselberth, J. R. (2018). Genetic bypass of essential RNA repair enzymes in budding yeast. RNA 24, 313-323. doi: 10.1261/rna.061788.117

Chu, H. Y., and Hopper, A. K. (2013). Genome-wide investigation of the role of the tRNA nuclear-cytoplasmic trafficking pathway in regulation of the yeast Saccharomyces cerevisiae transcriptome and proteome. Mol. Cell. Biol. 33, 4241-4254. doi: 10.1128/MCB.00785-13

Ciesla, M., and Boguta, M. (2008). Regulation of RNA polymerase III transcription by Maf1 protein. Acta Biochim. Pol. 55, 215-225.

Cook, A., Bono, F., Jinek, M., and Conti, E. (2007). Structural biology of nucleocytoplasmic transport. Annu. Rev. Biochem. 76, 647-671. doi: 10.1146/ annurev.biochem.76.052705.161529

Cook, A. G., Fukuhara, N., Jinek, M., and Conti, E. (2009). Structures of the tRNA export factor in the nuclear and cytosolic states. Nature 461, 60-65. doi: $10.1038 /$ nature 08394

Culver, G. M., McCraith, S. M., Consaul, S. A., Stanford, D. R., and Phizicky, E. M. (1997). A 2'-phosphotransferase implicated in tRNA splicing is essential in Saccharomyces cerevisiae. J. Biol. Chem. 272, 13203-13210. doi: 10.1074/ jbc.272.20.13203

Danpure, C. J. (1995). How can the products of a single gene be localized to more than one intracellular compartment? Trends Cell Biol. 5, 230-238. doi: 10.1016/S0962-8924(00)89016-9

De Robertis, E. M., Black, P., and Nishikura, K. (1981). Intranuclear location of the tRNA splicing enzymes. Cell 23, 89-93. doi: 10.1016/0092-8674(81)90273-7

Decatur, W. A., and Schnare, M. N. (2008). Different mechanisms for pseudouridine formation in yeast $5 \mathrm{~S}$ and 5.8S rRNAs. Mol. Cell. Biol. 28, 3089-3100. doi: 10.1128/MCB.01574-07

Delaleau, M., and Borden, K. L. (2015). Multiple export mechanisms for mRNAs. Cell 4, 452-473. doi: 10.3390/cells4030452

Dhakal, R., Tong, C., Anderson, S., Kashina, A. S., Cooperman, B., and Bau, H. H. (2018). Dynamics of intracellular stress-induced tRNA trafficking. Nucleic Acids Res.

Dhungel, N., and Hopper, A. K. (2012). Beyond tRNA cleavage: novel essential function for yeast tRNA splicing endonuclease unrelated to tRNA processing. Genes Dev. 26, 503-514. doi: 10.1101/gad.183004.111

Englert, M., and Beier, H. (2005). Plant tRNA ligases are multifunctional enzymes that have diverged in sequence and substrate specificity from RNA ligases of other phylogenetic origins. Nucleic Acids Res. 33, 388-399. doi: 10.1093/nar/gki174

Ernst, R. K., Bray, M., Rekosh, D., and Hammarskjold, M. L. (1997). A structured retroviral RNA element that mediates nucleocytoplasmic export of intron-containing RNA. Mol. Cell. Biol. 17, 135-144. doi: 10.1128/ MCB.17.1.135

Faza, M. B., Chang, Y., Occhipinti, L., Kemmler, S., and Panse, V. G. (2012). Role of Mex67-Mtr2 in the nuclear export of 40S pre-ribosomes. PLoS Genet. 8:e1002915. doi: 10.1371/journal.pgen.1002915

Feng, W., and Hopper, A. K. (2002). A Los1p-independent pathway for nuclear export of intronless tRNAs in Saccharomycescerevisiae. Proc. Natl. Acad. Sci. U. S. A. 99, 5412-5417.

Ferrezuelo, F., Steiner, B., Aldea, M., and Futcher, B. (2002). Biogenesis of yeast telomerase depends on the importin mtr10. Mol. Cell. Biol. 22, 6046-6055. doi: 10.1128/MCB.22.17.6046-6055.2002

Fischer, U., Huber, J., Boelens, W. C., Mattaj, I. W., and Luhrmann, R. (1995). The HIV-1 Rev activation domain is a nuclear export signal that accesses an export pathway used by specific cellular RNAs. Cell 82, 475-483. doi: 10.1016/0092-8674(95)90436-0
Gallardo, F., Olivier, C., Dandjinou, A. T., Wellinger, R. J., and Chartrand, P. (2008). TLC1 RNA nucleo-cytoplasmic trafficking links telomerase biogenesis to its recruitment to telomeres. EMBO J. 27, 748-757. doi: 10.1038/ emboj. 2008.21

Gilbert, W. V., Bell, T. A., and Schaening, C. (2016). Messenger RNA modifications: form, distribution, and function. Science 352, 1408-1412. doi: 10.1126/science. aad 8711

Gonzalez, T. N., Sidrauski, C., Dorfler, S., and Walter, P. (1999). Mechanism of non-spliceosomal mRNA splicing in the unfolded protein response pathway. EMBO J. 18, 3119-3132. doi: 10.1093/emboj/18.11.3119

Gopalan, V., Jarrous, N., and Krasilnikov, A. S. (2018). Chance and necessity in the evolution of RNase P. RNA 24, 1-5. doi: 10.1261/rna.063107.117

Gorlich, D., and Kutay, U. (1999). Transport between the cell nucleus and the cytoplasm. Annu. Rev. Cell Dev. Biol. 15, 607-660. doi: 10.1146/annurev. cellbio.15.1.607

Grosshans, H., Deinert, K., Hurt, E., and Simos, G. (2001). Biogenesis of the signal recognition particle (SRP) involves import of SRP proteins into the nucleolus, assembly with the SRP-RNA, and Xpolp-mediated export. J. Cell Biol. 153, 745-762. doi: 10.1083/jcb.153.4.745

Grosshans, H., Hurt, E., and Simos, G. (2000). An aminoacylation-dependent nuclear tRNA export pathway in yeast. Genes Dev. 14, 830-840.

Guo, M., and Schimmel, P. (2013). Essential nontranslational functions of tRNA synthetases. Nat. Chem. Biol. 9, 145-153. doi: 10.1038/nchembio.1158

Gutmann, B., Gobert, A., and Giege, P. (2012). PRORP proteins support RNase $\mathrm{P}$ activity in both organelles and the nucleus in Arabidopsis. Genes Dev. 26, 1022-1027. doi: 10.1101/gad.189514.112

Gwizdek, C., Ossareh-Nazari, B., Brownawell, A. M., Doglio, A., Bertrand, E., Macara, I. G., et al. (2003). Exportin-5 mediates nuclear export of minihelixcontaining RNAs. J. Biol. Chem. 278, 5505-5508. doi: 10.1074/jbc.C200668200

Hart, T., Chandrashekhar, M., Aregger, M., Steinhart, Z., Brown, K. R., MacLeod, G., et al. (2015). High-resolution CRISPR screens reveal fitness genes and genotype-specific cancer liabilities. Cell 163, 1515-1526. doi: 10.1016/j. cell.2015.11.015

Hellmuth, K., Lau, D. M., Bischoff, F. R., Kunzler, M., Hurt, E., and Simos, G. (1998). Yeast Los1p has properties of an exportin-like nucleocytoplasmic transport factor for tRNA. Mol. Cell. Biol. 18, 6374-6386. doi: 10.1128/ MCB.18.11.6374

Henics, T., Nagy, E., Oh, H. J., Csermely, P., von Gabain, A., and Subjeck, J. R. (1999). Mammalian Hsp70 and Hsp110 proteins bind to RNA motifs involved in mRNA stability. J. Biol. Chem. 274, 17318-17324. doi: $10.1074 /$ jbc. 274.24 .17318

Hopper, A. K. (1999). Nucleocytoplasmic transport: inside out regulation. Curr. Biol. 9, R803-R806. doi: 10.1016/S0960-9822(99)80494-1

Hopper, A. K. (2013). Transfer RNA post-transcriptional processing, turnover, and subcellular dynamics in the yeast Saccharomyces cerevisiae. Genetics 194, 43-67. doi: 10.1534/genetics.112.147470

Hopper, A. K., Pai, D. A., and Engelke, D. R. (2010). Cellular dynamics of tRNAs and their genes. FEBS Lett. 584, 310-317. doi: 10.1016/j. febslet.2009.11.053

Huang, H., Gao, Q., Peng, X., Choi, S. Y., Sarma, K., Ren, H., et al. (2011). piRNA-associated germline nuage formation and spermatogenesis require MitoPLD profusogenic mitochondrial-surface lipid signaling. Dev. Cell 20, 376-387. doi: 10.1016/j.devcel.2011.01.004

Huang, H. Y., and Hopper, A. K. (2014). Separate responses of karyopherins to glucose and amino acid availability regulate nucleocytoplasmic transport. Mol. Biol. Cell 25, 2840-2852.

Huang, H. Y., and Hopper, A. K. (2015). In vivo biochemical analyses reveal distinct roles of beta-importins and eEF1A in tRNA subcellular traffic. Genes Dev. 29, 772-783. doi: 10.1101/gad.258293.115

Huang, H. Y., and Hopper, A. K. (2016). Multiple layers of stress-induced regulation in tRNA biology. Life 6 .

Huh, W. K., Falvo, J. V., Gerke, L. C., Carroll, A. S., Howson, R. W., Weissman, J. S., et al. (2003). Global analysis of protein localization in budding yeast. Nature 425, 686-691. doi: 10.1038/nature02026

Hunter, C. A., Aukerman, M. J., Sun, H., Fokina, M., and Poethig, R. S. (2003). PAUSED encodes the Arabidopsis exportin-t ortholog. Plant Physiol. 132, 2135-2143. doi: 10.1104/pp.103.023309 
Hurt, D. J., Wang, S. S., Lin, Y. H., and Hopper, A. K. (1987). Cloning and characterization of LOS1, a Saccharomyces cerevisiae gene that affects tRNA splicing. Mol. Cell. Biol. 7, 1208-1216. doi: 10.1128/MCB.7.3.1208

Hurto, R. L., Tong, A. H., Boone, C., and Hopper, A. K. (2007). Inorganic phosphate deprivation causes tRNA nuclear accumulation via retrograde transport in Saccharomyces cerevisiae. Genetics 176, 841-852. doi: 10.1534/ genetics.106.069732

Huynh, L. N., Thangavel, M., Chen, T., Cottrell, R., Mitchell, J. M., and Praetorius-Ibba, M. (2010). Linking tRNA localization with activation of nutritional stress responses. Cell Cycle 9, 3112-3118. doi: 10.4161/cc.9.15.12525

Izumi, N., Shoji, K., Sakaguchi, Y., Honda, S., Kirino, Y., Suzuki, T., et al. (2016). Identification and functional analysis of the pre-piRNA $3^{\prime}$ trimmer in silkworms. Cell 164, 962-973. doi: 10.1016/j.cell.2016.01.008

Jackman, J. E., and Alfonzo, J. D. (2013). Transfer RNA modifications: nature's combinatorial chemistry playground. Wiley Interdiscip. Rev. RNA 4, 35-48. doi: $10.1002 /$ wrna.1144

Kaffman, A., Rank, N. M., O’Neill, E. M., Huang, L. S., and O'Shea, E. K. (1998). The receptor Msn5 exports the phosphorylated transcription factor Pho4 out of the nucleus. Nature 396, 482-486. doi: 10.1038/24898

Karijolich, J., and Yu, Y. T. (2010). Spliceosomal snRNA modifications and their function. RNA Biol. 7, 192-204.

Kelly, S. M., and Corbett, A. H. (2009). Messenger RNA export from the nucleus: a series of molecular wardrobe changes. Traffic 10, 1199-1208. doi: 10.1111/j.1600-0854.2009.00944.x

Kessler, A. C., Kulkarni, S. S., Paulines, M. J., Rubio, M. A. T., Limbach, P. A., Paris, Z., et al. (2018). Retrograde nuclear transport from the cytoplasm is required for tRNA(Tyr) maturation in T. brucei. RNA Biol. 15, 528-536.

Kim, Y. K., Kim, B., and Kim, V. N. (2016). Re-evaluation of the roles of DROSHA, export in 5, and DICER in microRNA biogenesis. Proc. Natl. Acad. Sci. U. S. A. 113, E1881-E1889. doi: 10.1073/pnas.1602532113

Knapp, G., Ogden, R. C., Peebles, C. L., and Abelson, J. (1979). Splicing of yeast tRNA precursors: structure of the reaction intermediates. Cell 18, 37-45. doi: 10.1016/0092-8674(79)90351-9

Kohler, A., and Hurt, E. (2007). Exporting RNA from the nucleus to the cytoplasm. Nat. Rev. Mol. Cell Biol. 8, 761-773. doi: 10.1038/nrm2255

Kosmaczewski, S. G., Edwards, T. J., Han, S. M., Eckwahl, M. J., Meyer, B. I., Peach, S., et al. (2014). The RtcB RNA ligase is an essential component of the metazoan unfolded protein response. EMBO Rep. 15, 1278-1285. doi: 10.15252/embr.201439531

Kramer, E. B., and Hopper, A. K. (2013). Retrograde transfer RNA nuclear import provides a new level of tRNA quality control in Saccharomyces cerevisiae. Proc. Natl. Acad. Sci. U. S. A. 110, 21042-21047.

Kutay, U., Lipowsky, G., Izaurralde, E., Bischoff, F. R., Schwarzmaier, P., Hartmann, E., et al. (1998). Identification of a tRNA-specific nuclear export receptor. Mol. Cell 1, 359-369. doi: 10.1016/S1097-2765(00)80036-2

Lemieux, B., Laterreur, N., Perederina, A., Noel, J. F., Dubois, M. L., Krasilnikov, A. S., et al. (2016). Active yeast telomerase shares subunits with ribonucleoproteins RNase P and RNase MRP. Cell 165, 1171-1181. doi: 10.1016/j.cell.2016.04.018

Lindahl, L., Bommankanti, A., Li, X., Hayden, L., Jones, A., Khan, M., et al. (2009). RNase MRP is required for entry of $35 \mathrm{~S}$ precursor rRNA into the canonical processing pathway. RNA 15, 1407-1416. doi: 10.1261/ rna.1302909

Lipowsky, G., Bischoff, F. R., Izaurralde, E., Kutay, U., Schafer, S., Gross, H. J., et al. (1999). Coordination of tRNA nuclear export with processing of tRNA. RNA 5, 539-549. doi: 10.1017/S1355838299982134

Lippai, M., Tirian, L., Boros, I., Mihaly, J., Erdelyi, M., Belecz, I., et al. (2000). The Ketel gene encodes a Drosophila homologue of importin-beta. Genetics $156,1889-1900$

Lund, E., and Dahlberg, J. E. (1998). Proofreading and aminoacylation of tRNAs before export from the nucleus. Science 282, 2082-2085. doi: 10.1126/ science.282.5396.2082

Lund, E., Guttinger, S., Calado, A., Dahlberg, J. E., and Kutay, U. (2004). Nuclear export of microRNA precursors. Science 303, 95-98. doi: 10.1126/ science. 1090599

Maertens, G. N., Cook, N. J., Wang, W., Hare, S., Gupta, S. S., Oztop, I., et al. (2014). Structural basis for nuclear import of splicing factors by human Transportin 3. Proc. Natl. Acad. Sci. U. S. A. 111, 2728-2733.
Martin, N. C., and Hopper, A. K. (1994). How single genes provide tRNA processing enzymes to mitochondria, nuclei and the cytosol. Biochimie 76, 1161-1167. doi: 10.1016/0300-9084(94)90045-0

Mingot, J. M., Vega, S., Cano, A., Portillo, F., and Nieto, M. A. (2013). eEF1A mediates the nuclear export of SNAG-containing proteins via the Exportin5aminoacyl-tRNA complex. Cell Rep. 5, 727-737. doi: 10.1016/j.celrep.2013.09.030

Miyagawa, R., Mizuno, R., Watanabe, K., and Ijiri, K. (2012). Formation of tRNA granules in the nucleus of heat-induced human cells. Biochem. Biophys. Res. Commun. 418, 149-155. doi: 10.1016/j.bbrc.2011.12.150

Miyauchi, K., Kimura, S., and Suzuki, T. (2013). A cyclic form of N6threonylcarbamoyladenosine as a widely distributed tRNA hypermodification. Nat. Chem. Biol. 9, 105-111. doi: 10.1038/nchembio.1137

Murthi, A., Shaheen, H. H., Huang, H. Y., Preston, M. A., Lai, T. P., Phizicky, E. M., et al. (2010). Regulation of tRNA bidirectional nuclearcytoplasmic trafficking in Saccharomyces cerevisiae. Mol. Biol. Cell 21, 639-649.

Nagashima, Y., Iwata, Y., Mishiba, K., and Koizumi, N. (2016). Arabidopsis tRNA ligase completes the cytoplasmic splicing of bZIP60 mRNA in the unfolded protein response. Biochem. Biophys. Res. Commun. 470, 941-946. doi: 10.1016/j.bbrc.2016.01.145

Ohira, T., and Suzuki, T. (2011). Retrograde nuclear import of tRNA precursors is required for modified base biogenesis in yeast. Proc. Natl. Acad. Sci. U. S. A. 108, 10502-10507.

Okamura, M., Inose, H., and Masuda, S. (2015). RNA export through the NPC in eukaryotes. Genes 6, 124-149. doi: 10.3390/genes6010124

Ossareh-Nazari, B., Maison, C., Black, B. E., Levesque, L., Paschal, B. M., and Dargemont, C. (2000). RanGTP-binding protein NXT1 facilitates nuclear export of different classes of RNA in vitro. Mol. Cell. Biol. 20, 4562-4571. doi: 10.1128/MCB.20.13.4562-4571.2000

Park, M. Y., Wu, G., Gonzalez-Sulser, A., Vaucheret, H., and Poethig, R. S. (2005). Nuclear processing and export of microRNAs in Arabidopsis. Proc. Natl. Acad. Sci. U. S. A. 102, 3691-3696.

Pasquinelli, A. E., Ernst, R. K., Lund, E., Grimm, C., Zapp, M. L., Rekosh, D., et al. (1997). The constitutive transport element (CTE) of Mason-Pfizer monkey virus (MPMV) accesses a cellular mRNA export pathway. EMBO J. 16, 7500-7510. doi: 10.1093/emboj/16.24.7500

Paushkin, S. V., Patel, M., Furia, B. S., Peltz, S. W., and Trotta, C. R. (2004). Identification of a human endonuclease complex reveals a link between tRNA splicing and pre-mRNA $3^{\prime}$ end formation. Cell 117, 311-321. doi: 10.1016/S0092-8674(04)00342-3

Peebles, C. L., Gegenheimer, P., and Abelson, J. (1983). Precise excision of intervening sequences from precursor tRNAs by a membrane-associated yeast endonuclease. Cell 32, 525-536. doi: 10.1016/0092-8674(83)90472-5

Phizicky, E. M., and Hopper, A. K. (2010). tRNA biology charges to the front. Genes Dev. 24, 1832-1860. doi: 10.1101/gad.1956510

Phizicky, E. M., Schwartz, R. C., and Abelson, J. (1986). Saccharomyces cerevisiae tRNA ligase. Purification of the protein and isolation of the structural gene. J. Biol. Chem. 261, 2978-2986.

Popow, J., Englert, M., Weitzer, S., Schleiffer, A., Mierzwa, B., Mechtler, K., et al. (2011). HSPC117 is the essential subunit of a human tRNA splicing ligase complex. Science 331, 760-764. doi: 10.1126/science.1197847

Popow, J., Schleiffer, A., and Martinez, J. (2012). Diversity and roles of $(\mathrm{t})$ RNA ligases. Cell. Mol. Life Sci. 69, 2657-2670. doi: 10.1007/s00018-012-0944-2

Pratt-Hyatt, M., Pai, D. A., Haeusler, R. A., Wozniak, G. G., Good, P. D., Miller, E. L., et al. (2013). Mod5 protein binds to tRNA gene complexes and affects local transcriptional silencing. Proc. Natl. Acad. Sci. U. S. A. 110, E3081-E3089. doi: 10.1073/pnas.1219946110

Reyes, V. M., and Abelson, J. (1988). Substrate recognition and splice site determination in yeast tRNA splicing. Cell 55, 719-730. doi: 10.1016/0092-8674(88)90230-9

Rintala-Dempsey, A. C., and Kothe, U. (2017). Eukaryotic stand-alone pseudouridine synthases - RNA modifying enzymes and emerging regulators of gene expression? RNA Biol. 14, 1185-1196. doi: 10.1080/15476286.2016.1276150

Sarkar, S., Azad, A. K., and Hopper, A. K. (1999). Nuclear tRNA aminoacylation and its role in nuclear export of endogenous tRNAs in Saccharomyces cerevisiae. Proc. Natl. Acad. Sci. U. S. A. 96, 14366-14371.

Sarkar, S., and Hopper, A. K. (1998). tRNA nuclear export in saccharomyces cerevisiae: in situ hybridization analysis. Mol. Biol. Cell 9, 3041-3055. 
Schwartz, S., Bernstein, D. A., Mumbach, M. R., Jovanovic, M., Herbst, R. H., Leon-Ricardo, B. X., et al. (2014). Transcriptome-wide mapping reveals widespread dynamic-regulated pseudouridylation of ncRNA and mRNA. Cell 159, 148-162. doi: 10.1016/j.cell.2014.08.028

Senger, B., Simos, G., Bischoff, F. R., Podtelejnikov, A., Mann, M., and Hurt, E. (1998). Mtr10p functions as a nuclear import receptor for the mRNA-binding protein Npl3p. EMBO J. 17, 2196-2207. doi: 10.1093/emboj/17.8.2196

Sengupta, J., Bussiere, C., Pallesen, J., West, M., Johnson, A. W., and Frank, J. (2010). Characterization of the nuclear export adaptor protein Nmd3 in association with the 60S ribosomal subunit. J. Cell Biol. 189, 1079-1086. doi: $10.1083 /$ jcb.201001124

Shaheen, H. H., and Hopper, A. K. (2005). Retrograde movement of tRNAs from the cytoplasm to the nucleus in Saccharomyces cerevisiae. Proc. Natl. Acad. Sci. U. S. A. 102, 11290-11295. doi: 10.1073/pnas.0503836102

Shaheen, H. H., Horetsky, R. L., Kimball, S. R., Murthi, A., Jefferson, L. S., and Hopper, A. K. (2007). Retrograde nuclear accumulation of cytoplasmic tRNA in rat hepatoma cells in response to amino acid deprivation. Proc. Natl. Acad. Sci. U. S. A. 104, 8845-8850. doi: 10.1073/pnas.0700765104

Shibata, S., Sasaki, M., Miki, T., Shimamoto, A., Furuichi, Y., Katahira, J., et al. (2006). Exportin-5 orthologues are functionally divergent among species. Nucleic Acids Res. 34, 4711-4721. doi: 10.1093/nar/gkl663

Sidrauski, C., Cox, J. S., and Walter, P. (1996). tRNA ligase is required for regulated mRNA splicing in the unfolded protein response. Cell 87, 405-413. doi: 10.1016/S0092-8674(00)81361-6

Sidrauski, C., and Walter, P. (1997). The transmembrane kinase Irelp is a site-specific endonuclease that initiates mRNA splicing in the unfolded protein response. Cell 90, 1031-1039. doi: 10.1016/S0092-8674(00)80369-4

Takano, A., Endo, T., and Yoshihisa, T. (2005). tRNA actively shuttles between the nucleus and cytosol in yeast. Science 309, 140-142. doi: 10.1126/ science. 1113346

Takano, A., Kajita, T., Mochizuki, M., Endo, T., and Yoshihisa, T. (2015). Cytosolic Hsp70 and co-chaperones constitute a novel system for tRNA import into the nucleus. eLife 4.

Takeiwa, T., Taniguchi, I., and Ohno, M. (2015). Exportin-5 mediates nuclear export of SRP RNA in vertebrates. Genes Cells 20, 281-291. doi: 10.1111/ gtc. 12218

Tanaka, N., Chakravarty, A. K., Maughan, B., and Shuman, S. (2011). Novel mechanism of RNA repair by RtcB via sequential $2^{\prime}, 3^{\prime}$-cyclic phosphodiesterase and $3^{\prime}$-phosphate/5' -hydroxyl ligation reactions. J. Biol. Chem. 286, 43134-43143. doi: $10.1074 /$ jbc.M111.302133

Tang, W., Tu, S., Lee, H. C., Weng, Z., and Mello, C. C. (2016). The RNase PARN-1 trims piRNA $3^{\prime}$ ends to promote transcriptome surveillance in C. elegans. Cell 164, 974-984. doi: 10.1016/j.cell.2016.02.008

Trotta, C. R., Miao, F., Arn, E. A., Stevens, S. W., Ho, C. K., Rauhut, R., et al. (1997). The yeast tRNA splicing endonuclease: a tetrameric enzyme with two active site subunits homologous to the archaeal tRNA endonucleases. Cell 89, 849-858. doi: 10.1016/S0092-8674(00)80270-6

Tsuboi, T., Yamazaki, R., Nobuta, R., Ikeuchi, K., Makino, S., Ohtaki, A., et al. (2015). The tRNA splicing endonuclease complex cleaves the mitochondrialocalized CBP1 mRNA. J. Biol. Chem. 290, 16021-16030. doi: 10.1074/jbc. M114.634592

Vasianovich, Y., and Wellinger, R. J. (2017). Life and death of yeast telomerase RNA. J. Mol. Biol. 429, 3242-3254. doi: 10.1016/j.jmb.2017.01.013

Wan, Y., and Hopper, A. K. (2018). From powerhouse to processing plant: conserved roles of mitochondrial outer membrane proteins in tRNA splicing. Genes Dev. 32, 1309-1314. doi: 10.1101/gad.316257.118

Wang, L. K., and Shuman, S. (2005). Structure-function analysis of yeast tRNA ligase. RNA 11, 966-975. doi: 10.1261/rna.2170305

Wang, T., Birsoy, K., Hughes, N. W., Krupczak, K. M., Post, Y., Wei, J. J., et al. (2015). Identification and characterization of essential genes in the human genome. Science 350, 1096-1101. doi: 10.1126/science.aac7041

Watanabe, K., Miyagawa, R., Tomikawa, C., Mizuno, R., Takahashi, A., Hori, H., et al. (2013). Degradation of initiator tRNAMet by Xrn1/2 via its accumulation in the nucleus of heat-treated HeLa cells. Nucleic Acids Res. 41, 4671-4685. doi: 10.1093/nar/gkt153

Watanabe, T., Chuma, S., Yamamoto, Y., Kuramochi-Miyagawa, S., Totoki, Y., Toyoda, A., et al. (2011). MITOPLD is a mitochondrial protein essential for nuage formation and piRNA biogenesis in the mouse germline. Dev. Cell 20, 364-375. doi: 10.1016/j.devcel.2011.01.005

Wen, W., Meinkoth, J. L., Tsien, R. Y., and Taylor, S. S. (1995). Identification of a signal for rapid export of proteins from the nucleus. Cell 82, 463-473. doi: 10.1016/0092-8674(95)90435-2

Whitney, M. L., Hurto, R. L., Shaheen, H. H., and Hopper, A. K. (2007). Rapid and reversible nuclear accumulation of cytoplasmic tRNA in response to nutrient availability. Mol. Biol. Cell 18, 2678-2686. doi: 10.1091/mbc.e07-01-0006

Wu, H., Becker, D., and Krebber, H. (2014). Telomerase RNA TLC1 shuttling to the cytoplasm requires mRNA export factors and is important for telomere maintenance. Cell Rep. 8, 1630-1638. doi: 10.1016/j.celrep.2014.08.021

Wu, J., Bao, A., Chatterjee, K., Wan, Y., and Hopper, A. K. (2015). Genomewide screen uncovers novel pathways for tRNA processing and nuclearcytoplasmic dynamics. Genes Dev. 29, 2633-2644. doi: 10.1101/gad.269803.115

Xiao, S., Scott, F., Fierke, C. A., and Engelke, D. R. (2002). Eukaryotic ribonuclease P: a plurality of ribonucleoprotein enzymes. Annu. Rev. Biochem. 71, 165-189. doi: 10.1146/annurev.biochem.71.110601.135352

Yakobov, N., Debard, S., Fischer, F., Senger, B., and Becker, H. D. (2018). Cytosolic aminoacyl-tRNA synthetases: unanticipated relocations for unexpected functions. Biochim. Biophys. Acta Gene Regul. Mech. 1861, 387-400. doi: 10.1016/j.bbagrm.2017.11.004

Yao, W., Roser, D., Kohler, A., Bradatsch, B., Bassler, J., and Hurt, E. (2007). Nuclear export of ribosomal $60 \mathrm{~S}$ subunits by the general mRNA export receptor Mex67-Mtr2. Mol. Cell 26, 51-62. doi: 10.1016/j.molcel.2007.02.018

Yi, R., Qin, Y., Macara, I. G., and Cullen, B. R. (2003). Exportin-5 mediates the nuclear export of pre-microRNAs and short hairpin RNAs. Genes Dev. 17, 3011-3016. doi: 10.1101/gad.1158803

Yoshida, K., and Blobel, G. (2001). The karyopherin Kap142p/Msn5p mediates nuclear import and nuclear export of different cargo proteins. J. Cell Biol. 152, 729-740. doi: 10.1083/jcb.152.4.729

Yoshihisa, T. (2014). Handling tRNA introns, archaeal way and eukaryotic way. Front. Genet. 5:213. doi: 10.3389/fgene.2014.00213

Yoshihisa, T., Ohshima, C., Yunoki-Esaki, K., and Endo, T. (2007). Cytoplasmic splicing of tRNA in Saccharomyces cerevisiae. Genes Cells 12, 285-297. doi 10.1111/j.1365-2443.2007.01056.x

Yoshihisa, T., Yunoki-Esaki, K., Ohshima, C., Tanaka, N., and Endo, T. (2003). Possibility of cytoplasmic pre-tRNA splicing: the yeast tRNA splicing endonuclease mainly localizes on the mitochondria. Mol. Biol. Cell 14, 3266-3279. doi: 10.1091/mbc.e02-11-0757

Zaitseva, L., Myers, R., and Fassati, A. (2006). tRNAs promote nuclear import of HIV-1 intracellular reverse transcription complexes. PLoS Biol. 4:e332. doi: 10.1371/journal.pbio.0040332

Zander, G., Hackmann, A., Bender, L., Becker, D., Lingner, T., Salinas, G., et al. (2016). mRNA quality control is bypassed for immediate export of stressresponsive transcripts. Nature 540, 593-596.

Zhou, L., Sokolskaja, E., Jolly, C., James, W., Cowley, S. A., Fassati, A., et al. (2011). Transportin 3 promotes a nuclear maturation step required for efficient HIV-1 integration. PLoS Pathog. 7:e1002194. doi: 10.1371/journal.ppat.1002194

Conflict of Interest Statement: The authors declare that the research was conducted in the absence of any commercial or financial relationships that could be construed as a potential conflict of interest.

Copyright (c) 2019 Hopper and Nostramo. This is an open-access article distributed under the terms of the Creative Commons Attribution License (CC BY). The use, distribution or reproduction in other forums is permitted, provided the original author(s) and the copyright owner(s) are credited and that the original publication in this journal is cited, in accordance with accepted academic practice. No use, distribution or reproduction is permitted which does not comply with these terms. 